\title{
Formulation and Evaluation of Itraconazole Proniosomal Gel for Topical Drug Delivery
}

\section{B Manasa $^{1 *}$, Dr. V Shanmugam ${ }^{2}$ and P Prakash ${ }^{3}$}

${ }^{1}$ M. Pharmacy, Department of Pharmaceutics, Sri Padmavathi School of Pharmacy,

Jawaharlal Nehru Technological University, Anantapur, India

${ }^{2}$ Associate Professor \& Head, Department of Pharmaceutics, Sri Padmavathi School

of Pharmacy, Anantapur, India

${ }^{3}$ M. Pharm, Assistant Professor, Sri Padmavathi School of Pharmacy, Jawaharlal

Nehru Technological University, Anantapur, India

*Corresponding Author: B Manasa, M. Pharmacy, Department of Pharmaceutics, Sri Padmavathi School of Pharmacy, Jawaharlal Nehru Technological University, Anantapur, India.
Received: July 20, 2020

Published: December 09, 2021

(C) All rights are reserved by B Manasa., et al.

\section{Abstract}

Proniosomes are vesicular systems, in which the vesicles are made up of non-ionic based surfactants, cholesterol and other additives. Semisolid liquid crystal gel (proniosomes) prepared by dissolving the surfactant in a minimal amount of an acceptable solvent, namely ethanol and then hydration with least amount of water to form a gel. Itraconazole is a BCS class-II Triazole anti fungal drug having greater first pass metabolism and lesser bioavailability. The Present study was aimed at preparing six formulations of Topical Proniosomal gels with different concentrations of surfactants and cholesterol. All the prepared formulations were evaluated for, \% Entrapment efficiency, In-vitro drug release studies, FT-IR studies, Vesicle size analysis Scanning electron microscopy and In vitro anti fungal studies. Among all the formulations IPN6 was found to exhibit optimum results for all the evaluation tests and In vitro drug release was found to be $90.10 \%$ at the end of 8 th hour. The drug release of all formulations followed Higuchi kinetics on fitting the drug release data to various kinetic models. Thus Proniosomal gels are the promising approach for Itraconazole to overcome the gastrointestinal side effects and to increase the drug bioavailability.

Keywords: Itraconazole; Proniosomal Gel; Coacervation Phase Separation Method; Non Ionic Surfactants; Soyalecithin; Cholesterol

\section{Introduction}

In recent times, no single drug delivery system fulfills all the criteria, but attempts have been made through novel approaches. Many novel approaches emerged covering various routes of administration, to achieve either controlled or targeted delivery. The prime aim of novel drug delivery is maintenance of the constant and effective drug level in the body and minimizing the side-effects and it also localizes the drug action by targeting the drug delivery by using drug carriers [5].
Vesicular drug delivery system

Vesicular drug delivery reduces the cost of therapy by improved bioavailability of medication. Especially in case of poorly soluble drugs. They can incorporate both hydrophilic and lipophilic drugs. Vesicular drug delivery systems delay drug elimination of rapidly metabolizable drugs, and function as sustained release systems. This system solves the problems of drug insolubility, instability, and rapid degradation. consequently number of vesicular delivery systems such as liposomes, niosomes, proniosomes, pharmacosomes 
etc. were developed, Niosomes are water soluble carrier particles, and these are dried to form a niosomal dispersion on brief agitation in hot aqueous media. This dehydrated product is called proniosomes. The proniosomal approach reduces the problems associated with dry, free flowing product, which is more stable during the storage and sterilization. The proniosomes are a versatile delivery system because of the ease of distribution, measuring, transfer, and storage.

Proniosomes were studied as alternatives to liposomes and other carrier systems for entrapping both polar and non polar or hydrophobic and hydrophilic drugs. The additional merits with proniosomes are low toxicity owing to non-ionic nature, no requirement of special precautions and conditions for formulation and preparations. However, stability is a main concern in the advancement of any formulation and even proniosomes have advantages as drug carriers, such as cost productivity, chemically stability in comparision to liposomes. They also minimize problems of physical stability such as fusion, leakage, sedimentation, and aggregation on storage.

Types of vesicular drug delivery systems

- Liposomes

- Virosomes

- $\quad$ Niosomes

- $\quad$ Proniosomes

- Transferosomes

- $\quad$ Proteasomes

- Sphingosomes

- Archaesome

- $\quad$ Ethosomes.

\section{Proniosomes}

Proniosomes are dry formulation of water soluble carrier particles that are coated with surfactant. They are rehydrated to form niosomal dispersion immediately before use on agitation in hot aqueous media within minutes. Proniosomes are physically stable during storage and transport. Drug encapsulated in vesicular structure of proniosomes prolong the existence of drug in the systematic circulation and enhances the penetration into target tissue and reduce toxicity.

\section{Action of proniosomes}

Proniosomes show their action after they are converted to Niosomes on hydration. Proniosomes Niosomes (on hydration). The hydration may occur by the addition of aqueous solvents. Proniosomes can entrap both hydrophilic and lipophilic drugs.

Proniosomes

Proniosomes are the niosomal formulation containing carrier and surfactants, which needs to be hydrated before being used. Proniosomes reduce the problems which are associated with niosomal formulation like as aggregation, leaking and fusion.

Carrier + Surfactant $=$ Proniosomes

Proniosomes + water $=$ Niosomes

Proniosomes are vesicular systems, in which the vesicles are made up of non-ionic based surfactants, cholesterol and other additives. Semisolid liquid crystal gel (proniosomes) prepared by dissolving the surfactant in a minimal amount of an acceptable solvent, namely ethanol and then hydration with least amount of water to form a gel. These structures are liquid crystalline compact niosomes hybrids that can be converted into niosomes immediately upon hydration or used as such in the topical/transdermal applications.

\section{Advantages of proniosomes}

- $\quad$ Both the non-ionic surfactants and phospholipids in proniosomes can act as penetration enhancers and help in diffusion of the drug.

- Proniosomes have higher advantages such as additional convenience of dosing, storage, transportation, and distribution.

- $\quad$ They avoid the problems associated with either the aqueous noisome dispersion, such as problems of physical stability, aggregation, fusion, and leakage.

- Proniosomes also avoid problems associated with liposomes like degradation by hydrolysis or oxidation as well as sedimentation, aggregation or fusion during storage. 
- $\quad$ Proniosomes not only offer a promising means of drug delivery, but also could enhance the recovery rate of the skin barrier.

Structure

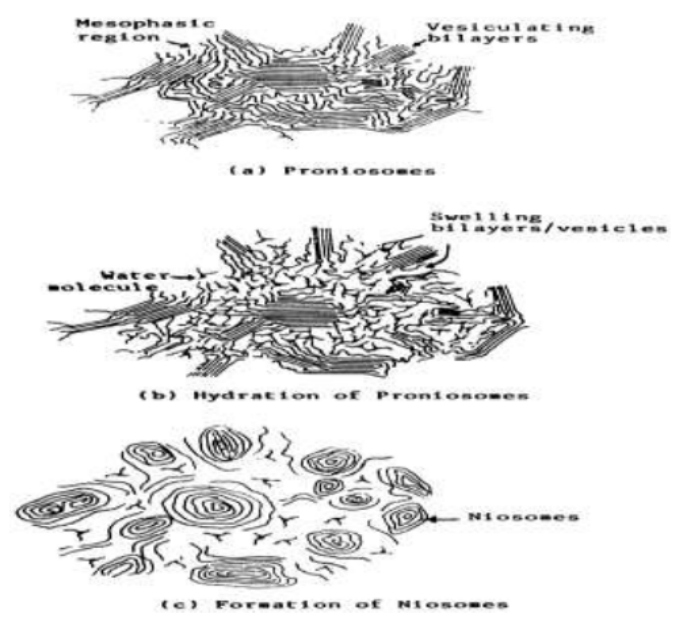

Figure 1: Structure of (a) Proniosomes (b) Hydration of proniosomes (c) Formation of niosomes.

\section{Formulation aspects of proniosomes}

\section{Surfactants}

Hydrophillc Lipophillic Balance (HLB) is the basis for the selection of surfactant. The HLB value indicates that the surfactant will form vesicle or not. It is reported that the HLB value between 4 and 8 are good candidates for vesicle formation. Hydrophillc surfactants, due to their high aqueous solubility on hydration. High HLB value reduces the surface free energy and allows vesicle formation of large size. Span 40 and span 60 have high HLB value, which results in reduced surface free energy, hence large size vesicles are formed, which gives a larger area exposed to skin and dissolution medium. All spans have high Phase Transition Temperature hence good encapsulation efficiency, less leakage of drug. Encapsulation efficiency of tween is low as compared to spans.

\section{Lecithin}

Lecithin as a complex mixture of acetone in soluble phosphatides that consists chiefly of phosphatidylcholine, phosphatidylethanol- amine, phosphatidylserine, and phosphatidylinositol, combined with various amounts of other substances such as triglycerides, fatty acids, and carbohydrates as separated from a crude vegetable oil source. The composition of lecithin (and hence also its physical properties) varies enormously depending upon the source of the lecithin and the degree of purification. Egg lecithin, for example, contains $69 \%$ phosphatidylcholine and $24 \%$ phosphatidylethanolamine, while soybean lecithin contains $21 \%$ phosphatidylcholine, $22 \%$ phosphatidylethanolamine, and 19\% phosphatidylinositol, along with other components.

In proniosomal gel, lecithin plays important role like

- Lecithin acts as a penetration enhancer

- Increases entrapment efficiency due to high phase transition temperature

- $\quad$ Prevents leakage of the drug from vesicle

- $\quad$ Reduces vesicle size due to increase in the hydrophobicity (vesicle composed of soya lecithin is of larger size than that composed of egg lecithin).

Egg lecithin contains saturated fatty acid while soya lecithin contains unsaturated fatty acids, oleic acid and linoleic acid, hence soya lecithin is having good penetrability over egg lecithin.

\section{Cholesterol}

Cholesterol is an important component of proniosomal vesicle. As it influences stability and permeability of vesicle. It was found that entrapment efficiency increase with increase in cholesterol content up to a certain limit, at higher concentration it has lowering effect on entrapment efficiency. This is because the cholesterol molecule act as vesicular cement which accommodates itself in the molecular cavities formed.

\section{Solvent}

Alcohol used in Proniosomes has a great effect on vesicle size and drug permeation rate. Vesicles formed from different alcohols are of different size and they follow the order: Ethanol > Propanol > Butanol > Isopropanol. Ethanol has greater solubility in water hence leads to formation of highest size of vesicles instead of Isopropanol which forms smallest size of vesicle due to branched chain present. 
Drug

The drug selection criteria could be based on the following assumptions.

- $\quad$ Low aqueous solubility of drugs.

- $\quad$ High dosage frequency of drugs.

- Short half-life.

- $\quad$ Controlled drug delivery suitable drugs.

- $\quad$ Higher adverse drug reaction drugs [13].

Proniosome preparation methods

\section{Slurry method}

This method involves preparation of slurry in a round bottom flask using carrier and surfactant solution. Additional amount of organic solvent can be added if desired to obtain slurry. The slurry is dried by applying vaccum to get free-flowing powder of proniosomes. The powder should be stored at $4^{\circ} \mathrm{C}$ in a sealed container. The time required to produce proniosomes is independent on the ratio of carrier material to surfactant solution and appears to be scalable.

\section{Co-acervation phase separation method}

This is the widely used method to prepare proniosomal gel. Weighed quantities of drug, lipid and surfactants are taken in a dry wide-mouthed glass beaker followed by the addition of solvent. The ingredients are mixed well and warmed over water bath at 60$70^{\circ} \mathrm{C}$ until the surfactant mixture dissolves completely. During the process care must be taken to prevent loss of any solvent due to evaporation. Finally, the aqueous phase is added to the mixture and warmed on water bath. The resultant solution is cooled overnight to obtain proniosomal gel.

\section{Spray-coating method}

In this method, proniosomes are prepared by spraying surfactant in organic solvent onto a carrier/coating material followed by evaporation of solvent. The surfactant forms a thin film on the carrier and subsequent hydration causes formation of multi-lamellar vesicles [16].
Role of proniosomes in drug targeting through transdermal delivery

The major barrier to transdermal delivery of drugs is stratum corneum. Vesicular delivery via skin is beneficial in that drugs, which permeate via skin and reaches systemic circulation. For transdermal delivery, proniosomes are the best vesicular system because they act as a drug reservoir for a prolonged period of time and increases skin permeation. The formulation of drugs into proniosomes also helps in better physical and chemical stability of the drug and the vesicular nature of the delivery system helps the drug to permeate through skin with an ease and helps in reaching systemic circulation and the target site without losing any drug activity and providing better therapeutic efficacy [16].

\section{Applications of proniosomes}

\section{Targeting of bioactive agents}

One of the most useful aspects of proniosomes is their ability to target drugs to particular area. Proniosomes can be used to target drugs to the reticulo-endothelial system. The reticulo-endothelium system (RES) preferentially takes up proniosomes vesicles. The uptake of proniosomes is controlled by circulating serum factors called opsonins. Such localization of drugs is utilized to treat tumors in animals known to metastasize to the liver and spleen. This localization of the drugs can also be used for treating parasitic infections of the liver. Proniosomes can also be utilized for targeting drugs to organs other than the RES. A carrier system (such as antibodies) can be attached to proniosomes (as immunoglobin bind readily to the lipid surface of the noisome) to target them to specific organ [2].

\section{Anti-neoplatic treatment}

Most of the antineoplastic drugs cause severe side effects. Proniosomes can alter the metabolism; prolong circulation and half life of the drug, thus decreasing the side effects of the drugs. Proniosomal entrapment of doxorubicin and methotrexate showed beneficial effects over the unentrapped drugs, such as decreased rate of proliferation of the tumor and higher plasma levels accompanied by slower elimination. 


\section{Treatment of leishmaniasis}

Leishmanasis is a disease in which a parasite of the genus leishmania invades the cells of the liver and spleen. Commonly prescribed drugs for the treatment are derivatives of antimony (antimonials), which are in higher concentrations causes cardiac, liver and kidney damage. Use of proniosomes showed that it was possible to administer higher levels of the drug without triggering the side effects, and thus allowed greater efficacy in treatment [2].

\section{Delivery of peptide drugs}

Oral peptide drug delivery has long been faced with a challenge of bypassing the enzymes which would breakdown the peptide. Use of proniosomes aimed to successfully protect the peptides from gastrointestinal peptide breakdown. In a study, oral delivery of a vasopressin derivative entrapped in proniosomes showed highest entrapment of the drug and significant increase in the stability of the incorporated peptide.

\section{Uses in studying immune response}

Proniosomes are used in studying immune response due to their immunological selectivity, low toxicity and greater stability. Proniosomes are being used to study the nature of the immune response provoked by antigens.

\section{Transdermal drug delivery systems}

One of the most useful aspects of proniosomes is that they greatly enhance the uptake of drugs through the skin. Transdermal drug delivery utilizing proniosomal technology is widely used in cosmetics; In fact, it was one of the first uses of the niosomes. Topical use of proniosome entrapped antibiotics to treat acne is done. The penetration of the drugs through the skin is greatly increased as compared to un-entrapped drug. Recently, transdermal vaccines utilizing proniosomal technology is also being researched. The proniosomes (along with liposomes and transferomes) can be utilized for topical immunization using tetanus toxoid. However, the current technology in proniosomes allows only a weak immune response, and thus more research to be done in this field.

\section{Sustained release drug delivery}

Sustained release action of proniosomes can be applied to drugs with low therapeutic index and low water solubility since those could be maintained in the circulation via proniosomal encapsulation.

\section{Localized drug action}

Drug delivery through proniosomes is one of the approaches to achieve localized drug action, since their size and low penetrability through epithelium and connective tissue keeps the drug localized at the site of administration. Localized drug action results in enhancement of efficacy of potency of the drug and at the same time reduces its systemic toxic effects e.g. Antimonials encapsulated within proniosomes are taken up by mononuclear cells resulting in localization of drug, increase in potency and hence decrease both in dose and toxicity. The evolution of proniosomal drug delivery technology is still at an infancy stage, but this type of drug delivery system has promise in cancer chemotherapy and anti-leishmanial therapy [3].

\section{Applications in cardiology}

Proniosomes are used as carriers for the transdermal delivery of captopril for the treatment of hypertension. The study shows that the proniosomal system causes extended release of the drug in the body. Encapsulation of the drug is carried out using Sorbitan esters, Cholesterol and lecithin.

\section{Application in diabetes}

Skin permeation mechanism of furesamide proniosomes is performed in which span, soya, lecithin, diacetyl phosphate, and cholesterol were used. Over all findings suggest that the proniosomes serve as non-invasive delivery of furesamide.

\section{Hormonal therapy}

Work had been performed on proniosome based transdermal delivery of levonorgestrel the emergency contraceptive. The structure of the niosome was liquid crystalline compact hybrid. The system was tested for particle size, encapsulation efficiency, stability study, in vivo and in vitro study. Bioassay for progestational activity was also performed. It included endometrial assay and blockade of development of corpora lutea.

\section{Delivery of peptide drugs}

Oral peptide drug delivery has a drawback of bypassing the enzymes, which would breakdown the peptide and protein bonds. Niosomes were used to successfully protect the peptides from gastrointestinal peptide breakdown. Oral delivery of vasopressin derivative entrapped in niosomes showed that entrapment of the drug significantly increased the stability of the peptide. 
Uses in studying immune response

Immune response was studied using niosomes due to their immunological selectivity, low toxicity and greater stability. Niosomes and proniosomes are being used to study the nature of the immune response provoked by antigens.

\section{Niosomes as carriers for hemoglobin}

Blood has many carrier proteins present in it. Niosomes can be used as carriers for hemoglobin within the blood. The niosomal or the proniosomal vesicle is permeable to oxygen and hence it acts as a carrier for hemoglobin in patients.

\section{Other applications}

Sustained release

Sustained release action of niosomes can be applied to drugs with low therapeutic index and low water solubility since those could be maintained in the circulation via niosomal encapsulation.

Itraconazole has a broader spectrum of activity than fluconazole (but not as broad as voriconazole or posaconazole). In particular, it is active against Aspergillus, which fluconazole is not. It is also licensed for use in blastomycosis, sporotrichosis, histoplasmosis, and onychomycosis. Itraconazole is over 99\% protein-bound and has virtually no penetration into cerebrospinal fluid. Therefore, it should never be used to treat meningitis or other central nervous system infections. According to the Johns Hopkins Abx Guide, it has "negligible CSF penetration, however treatment has been successful for cryptococcal and coccidioidal meningitis" [13].

It is also prescribed for systemic infections, such as aspergillosis, candidiasis, and cryptococcosis, where other antifungal drugs are inappropriate or ineffective.

Itraconazole has also recently been explored as an anticancer agent for patients with basal cell carcinoma, non-small cell lung cancer, and prostate cancer. For example, in a phase II study involving men with advanced prostate cancer, high-dose itraconazole (600 mg/day) was associated with significant PSA responses and a delay in tumor progression. Itraconazole also showed activity in a phase II trial in men with non-small cell lung cancer when it was combined with the chemotherapy agent, pemetrexed.

Itraconazole should not be used for treatment of onchomycosis in patients with a history of heart failure. It should be discon- tinued if signs and symptoms of heart failure occur. Symptoms of heart failure include fatigue, edema (fluid retention), shortness of breath, nausea, abdominal pain, and inability to sleep unless sitting upright. Use of calcium channel blockers may increase the risk of heart failure associated with itraconazole (see drug interactions).

\section{Review Literature}

Ibrahim A. Alsarra (2009) has worked on to Piroxicam loaded Niosomes prepared by co-acervation phase separation method. Using non-ionic surfactants, SoyaLecithin and cholesterol. And these prepared proniosomal gels were evaluated for surface morphology, entrapment efficiency, In vitro permeation studies were performed. Niosomes prepared using span 60 showed a higher release rate than those prepared using Non-ionic surfactants span 20 and span 80 , While those prepared from tween showed higher release rate than formula prepared with span. These results are very encouraging and suggest that niosomes can act as promising carriers offering an alternative approach for transdermal drug delivery of piroxicam [8].

Prabhakar Reddy Veerareddy., et al. (2012) has investigated to formulated and evaluated Isradipine proniosomes for enhances the oral bioavailability. This proniosomes were prepared by film deposition on carrier's method using various molar ratios of non- ionic surfactants such as span 20, Span 40, Span 60 and span 80.with cholesterol as membrane stabilizing agent. These proniosomes were characterized for optical microscopy, Scanning electron microscopy, Fourier transform infrared spectroscopy, Differential scanning colorimetry and x-ray diffractometry studies were performed for solid state properties of the drug. Dissolution studies for this prepared proniosomes are higher when compared to the pure drug [10].

H.O Ammar., et al. (2011) has Developed to formulated the tenoxicam proniosomes for transdermal drug delivery for the treatment of rheumatic diseases. This tenoxicam proniosomes prepared by co-acervation phase separation by using different ratios of Non-ionic surfactants, soya lecithin and cholesterol. And these proniosomes characterized by optical microscopy, In vitro drug release, drug entrapment efficiency, stability and ex-vivo permeation studies [7].

Adnan Azeem., et al. (2008) has studied on to the frusemide proniosomes for transdermal drug delivery to enhance its skin permeation and these frusemide proniosomes were prepared by 
co-acervation phase separation method by using different ratios of span40, soyalecithin and cholesterol. The effect of various formulation variables on the transdermal flux, amount of drug deposited in skin, and plasma level of drug were studied. The prepared frusemide were evaluated for Entrapment efficiency, Ex vivo permeation studies [2].

Anahita Fathi azarbayjani., et al. (2009) has explained Haloperidol proniosomes with non-ionic surfactants were prepared by modified literature method by using different types and ratios of non-ionic surfactants. And these Haloperidol proniosomes were evaluated and characterized for Entrapment efficiency, in vitro permeation studies, stability studies, scanning electron microscopy studies were performed. Entrapment efficiency of Haloperidol was very high in all formulations. Stability studies performed at $4^{\circ} \mathrm{C}$ and $25^{\circ} \mathrm{C}$ for a period of 6 weeks did not reveal any significant drug leakage $(p>0.05)[1]$.

Reena Thakur., et al. (2009) has investigated the feasibility of proniosomes as transdermal drug delivery system for losartan potassium. The proniosomes were prepared by co-acervation phase separation method by using different non ionic surfactants, such as Span 20, Span 40, Span 60, Span 80, Tween 20, Tween 40, and Tween 80. Prepared proniosomes were evaluated for Entrapment efficiency, Microscopic evaluation, in vitro skin permeation studies, pharmacokinetic and statistical analysis. Proniosomal transdermal therapeutic system (PNP-H) was found to be the optimized one as it gave better release of drug and better permeation in a steadystate manner over a desired period of time, that is, $24 \mathrm{~h}$ through rat skin [11].

Shweta Vashist., et al. (2015) has worked on to formulated and evaluated the proniosomal gel of Diclofenac sodium by using 32 factorial design. The proniosomes were prepared by co-acervation phase separation method by using different concentration of surfactant (span 60) and cholesterol. They were optimized using 32 factorial designs to study the effect of independent variables, i.e. concentration of span 60 (X1) and cholesterol (X2) on dependent variables like vesicle size, $\%$ entrapment efficiency and $\%$ drug release at $24 \mathrm{hrs}$. The prepared proniosomal gel was characterized for $\mathrm{pH}$, vesicle size, viscosity, spreadability, entrapment efficiency and ex vivo drug permeation study The optimized formulation was found to be F5 containing medium concentration of span 60 (1350 $\mathrm{mg}$ ) and medium concentration of cholesterol (250 mg). Results suggest that proniosomal gel can enhance delivery of diclofenac through skin and can improve the bioavailability of drug [12].

Harini Chowdary V., et al. (2014) has investigated to encapsulate the ibuprofen with proniosomal gel. Ibuprofen proniosomal gel were prepared by using co-acervation phase separation meth- od by different concentrations of Span 20/Span 80 and soya lecithin The prepared proniosomal gels were evaluated for chemical incompatibility by FT-IR, vesicle size analysis, encapsulation efficiency, in vitro drug permeation and in vitro drug release kinetics were performed. The vesicular diameter was less for proniosomes prepared using Span 80 (low HLB). The encapsulation efficiency was more for the proniosomal gels prepared using Span 20. The optimized proniosomal gel formulation PN3 containing Span 20 exhibited prolonged ibuprofen release profiles. Fickian diffusion mechanism was observed with the PN3 formulation which was due to the sustained release property. The results indicated that the proniosomal gel would be an effective transdermal delivery system for ibuprofen [15].

Srividhya Vardhani CH., (2016) has worked on to formulated and evaluated topical proniosomal gel of itraconazole prepared by co-acervation phase separation method using different concentrations of span 20,span 80,soyalecithin and cholesterol. All the prepared formulations were evaluated for Physical appearance, $\mathrm{pH}$, Vesicle size analysis, Vesicle shape and surface characteristics, \% Entrapment efficiency, In-vitro drug release studies and Stability studies. Among all the formulations F4 was found to exhibit optimum results for all the evaluation tests and In vitro drug release was found to be $91.9 \%$ at the end of $9^{\text {th }}$ hour. Thus Proniosomal gels are the promising approach for Itraconazole to overcome the gastrointestinal side effects and to increase the drug bioavailability [14].

Dr. Sanju nanda., et al. (2014) has developed to formulated and evaluated for transdermal gel of ketorolac tromethamine In vitro dissolution study was carried out for carbopol gel, proniosomal gel and marketed gel in phosphate buffer $\mathrm{pH}$ 7.4. The high release rate formulation is optimized using response surface methodology by face centered central composite design (FCCCD). DSC and FTIR were used to characterize the gels. In the present study, various batches of gel of KT were prepared along with carbopol 940 and PEG 400 in different combinations as per the design expert (8.0.5). The prepared gels were evaluated for clarity, homogeneity, viscosity, drug content, $\mathrm{pH}$, spreadability, extrudability, in vitro permeation studies. No chemical interaction was found between KT and polymers. KT8 was found to be optimized formulation [4].

Gagandeep Benipal., et al. (2015) has worked on to designed development of ketoconazole proniosomal gel. Prepared by coacervation phase separation method. by using different non-ionic surfactants span 20, Span 40, Span 60, Span 80, Tween 20, Tween 60, Tween 80. Prepared proniosomes were evaluated for Entrapment efficiency, vesicle size and shape, in vitro release and stability. The entrapment efficiency of drug in optimized formulation (F3) containing Span 60 is high (94.93\%) moreover, the extent of drug 
permeation through the membrane from the optimized formula was also quite high (93.52\%) after $24 \mathrm{hrs}$. Concentration of cholesterol and lipid also plays an imp role in the entrapment efficiency of formed proniosomes [6].

\section{Aim}

The aim of present work is to Formulate and Evaluate Itraconazole Proniosomal gel for Topical drug delivery.

Objective

The main objective of this study is

- To avoid the first pass metabolism,

- Reduce the gastrointestinal side effects,

- Improved the drug bioavailability,

- It is most widely used to treat fungal infections like Systemic mycosis, Histoplasmosis, Onchomycois, Aspergillosis, Chromo mycosis, Candidiasis, Blastomycosis and Cryotococcal Meningitis.

Plan of work

- Analytical estimation of Itraconazole using UV-Visible Spectrophotometric method.

- Standard plot of Itraconazole

- Melting point Determination

- $\quad$ Drug- Excipient compatibility FT-IR

- Formulation And Evaluation of Itraconazole Proniosomal gel for Drug Delivery by using Co-acervation phase separation method.

- Evaluation of Proniosomes

- $\quad$ Entrapment efficiency

- In vitro drug release studies

- Drug content

- $\quad$ Drug release kinetic studies

- Characterization of optimized Proniosomes

- $\quad$ Optical microscopy

- Zeta potential by zeta sizer.

- $\quad$ SEM

- Anti-fungal studies

- Evaluation of proniosomal gel

- $\mathrm{pH}$
- $\quad$ Physical appearance and Homogenicity

- Clarity

- $\quad$ Spreadability

- Extrudability

- Viscosity

Excipients profiles

Drug profile

Molecular Weight: $705.641 \mathrm{~g} / \mathrm{mol}$

Molecular Formula: C35H38Cl2N8O4

Structural Formula:

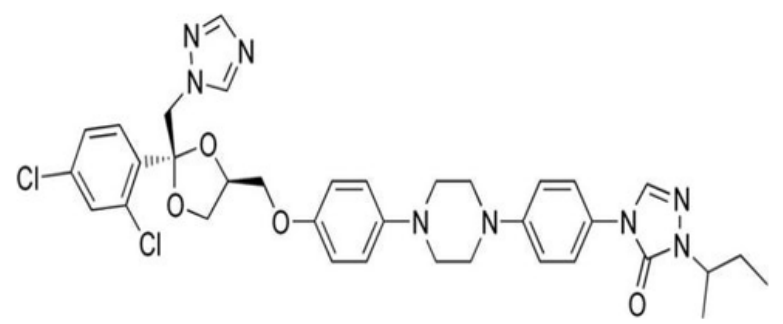

Melting Point: $166^{\circ} \mathrm{C}$

Solubility: Insoluble in water,

Slightly soluble in alcohols,

Soluble in DMSO and dimethylformamide

Storage temperature: $2-8^{\circ} \mathrm{C}$

Pharmacokinetics:

Absorption: The Absolute oral bioavailability of itraconazole is $55 \%$ and is maximal when taken with full meal.

Volume of Distribution: 796 -185L

Protein Binding: 99.8\%

Half life: 21 Hours

Route of Elimination:

- Itraconazole is metabolized by the cytochrome P-450 3A4 isoenzyme system in the liver, resulting in the formation of several metabolites including hydroxyitraconazole.The major metabolite.

- $\quad$ Fecal excretion of the parent drug varies between 3-18\% of the dose.

- Renal excretion of the parent drug is less than $0.03 \%$ of the dose.

Non-ionic surfactants

SPAN 20

Non proprietary Name: USP: Sorbitan monolaurate 
HLB value: 8.6

Functional category: o/w Emulsifying agent, Solubilizing agent, wetting agent and for uniform vesicle formation.

Description: Span 20 is a yellow coloured viscous liquid.

Solubility: Soluble or dispersible in oils; Soluble in most organic solvents.in water although insoluble, They are generally dispersible.

Pharmaceutical applications: They are mainly used as emulsifying agents in the preparation of creams, Emulsions, and ointments for topical application.

\section{Soya lecithin}

- Nonproprietary Names: USP-NF: Lecithin

- Synonyms: E322; egg lecithin; LSC 5050; LSC 6040; mixed soybean phosphatides; ovolecithin; Phosal 53 MCT; Phospholipon $100 \mathrm{H}$; ProKote LSC; soybean lecithin; soybean phospholipids; Sternpur; vegetable lecithin.

Structural formula

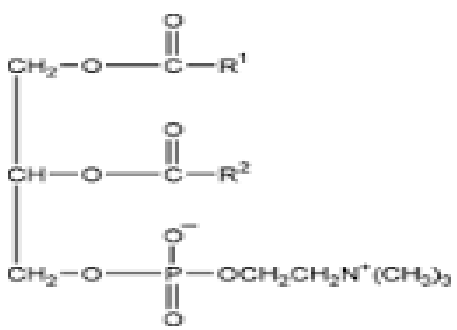

\section{Functional category}

Emollient; emulsifying agent; solubilizing agent.

\section{Physicochemical properties}

\section{Description}

Lecithins vary greatly in their physical form, from viscous semi liquids to powders, depending upon the free fatty acid content. They may also vary in color from brown to light yellow, depending upon whether they are bleached or unbleached or on the degree of purity. When they are exposed to air, rapid oxidation occurs, also resulting in a dark yellow or brown color. Lecithins have practically no odor. Those derived from vegetable sources have a bland or nut- like taste, similar to that of soybean oil.

Density

- $\quad 0.97 \mathrm{~g} / \mathrm{cm}^{3}$ for liquid lecithin.

- $\quad 0.5 \mathrm{~g} / \mathrm{cm}^{3}$ for powdered lecithin.

\section{Solubility}

Lecithins are soluble in aliphatic and aromatic hydrocarbons, halogenated hydrocarbons, mineral oil, and fatty acids. They are practically insoluble in cold vegetable and animal oils, polar solvents, and water. When mixed with water, however, lecithins hydrate to form emulsions.

\section{Stability and storage conditions}

Lecithins decompose at extreme $\mathrm{pH}$. They are also hygroscopic and subject to microbial degradation. When heated, lecithins oxidize, darken, and decompose. Temperatures of $160-180^{\circ} \mathrm{C}$ will cause degradation within 24 hours. Fluid or waxy lecithin grades should be stored at room temperature or above; temperatures below $10^{\circ} \mathrm{C}$ may cause separation. All lecithin grades should be stored in well-closed containers protected from light and oxidation. Purified solid lecithins should be stored in tightly closed containers at subfreezing temperatures.

\section{Incompatibilities}

Incompatible with esterases owing to hydrolysis.

\section{Applications in pharmaceutical formulation or technology}

Lecithins are mainly used in pharmaceutical products as dispersing, emulsifying, and stabilizing agents, and are included in intramuscular and intravenous injections, parenteral nutrition formulations, and topical products such as creams and ointments. Lecithins are also used in suppository bases, to reduce the brittleness of suppositories, and have been investigated for their absorption-enhancing properties in an intranasal insulin formulation. Lecithins are also commonly used as a component of enteral and parenteral nutrition formulations.

\section{Tween 20}

Non proprietary Name: USP: Polysorbate 20. 
HLB value: 16.7 .

Functional category: Emulsifying agent, Solubilizing agent, wetting agent.

Description: A lemon to amber-coloured oily liquid at $25^{\circ} \mathrm{C}$ with a faint characteristic odour.

Solubility: Soluble in water, ethanol, methanol, ethyl acetate, and dioxine. Insoluble in mineral oil and petroleum ether.

Pharmaceutical Applications: Polysorbate 20 is used as an excipient in pharmaceutical applications to stabilize emulsions and suspensions.

\section{MAISINE 35-1}

Generic Name: Glyceryl Monolinoleate

Molecular weight: $354.42 \mathrm{~g} / \mathrm{mol}$

Molecular formula: $\mathrm{C}_{21} \mathrm{H}_{38} \mathrm{O}_{4}$

Physical properties

Boiling point: $239^{\circ} \mathrm{C}$

Melting point: $35.5^{\circ} \mathrm{C}$

Solubility: Insoluble in water, Freely soluble in Methylene chloride

Density: $0.971-0.974 \mathrm{~g} / \mathrm{cm}^{3}$

Applications:

Suitable for hard and soft gelatin capsules

Good solvent for lipophilic API.

Pre formulation studies

Spectroscopic studies

Preparation of phosphate buffer of pH 7.4

Dissolve 6.8 grams of potassium dihydrogen orthophosphate, 1.56 grams of sodium hydroxide was added to distilled water and then volume was adjusted to $1000 \mathrm{ml}$ with distilled water.

\section{Calibration curve of itraconazole}

Itraconazole is a white fine powder which is practically insoluble in water. Though several methods are reported for its estimation, the UV- spectro photometric method is employed in the study.
Itraconazole shows maximum absorbance at 248nm. Based on this information standard graph was constructed.

\section{Preparation of calibration curve of itraconazole}

$10 \mathrm{mg}$ of Itraconazole was accurately weighed and transferred in to $50 \mathrm{ml}$ standard flask and then volume was made up of $50 \mathrm{ml}$ with Ethanol. Pipette out $0.2 \mathrm{ml}, 0.4 \mathrm{ml}, 0.6 \mathrm{ml}, 0.8 \mathrm{ml}$ and $1 \mathrm{ml}$ from above solution transferred in to the $10 \mathrm{ml}$ standard flask and diluted to $10 \mathrm{ml}$ with phosphate buffer of PH 7.4 as shown in below.

$0.2 \mathrm{ml} \rightarrow$ Diluted phosphate buffer of PH $7.4 \rightarrow 10 \mathrm{ml} \rightarrow 2 \mu \mathrm{g} / \mathrm{ml}$.

$0.4 \mathrm{ml} \rightarrow$ Diluted phosphate buffer of PH $7.4 \rightarrow 10 \mathrm{ml} \rightarrow 4 \mu \mathrm{g} / \mathrm{ml}$.

$0.6 \mathrm{ml} \rightarrow$ Diluted phosphate buffer of PH $7.4 \rightarrow 10 \mathrm{ml} \rightarrow 6 \mu \mathrm{g} / \mathrm{ml}$.

$0.8 \mathrm{ml} \rightarrow$ Diluted phosphate buffer of $\mathrm{pH} 7.4 \rightarrow 10 \mathrm{ml} \rightarrow 8 \mu \mathrm{g} / \mathrm{ml}$.

$1.0 \mathrm{ml} \rightarrow$ Diluted phosphate buffer of PH $7.4 \rightarrow 10 \mathrm{ml} \rightarrow 10 \mu \mathrm{g} / \mathrm{ml}$.

Absorbance of the prepared solutions was determined spectro photo metrically at $248 \mathrm{~nm}$.the experiment was repeated for six times. Phosphate buffer of PH 7.4 was used as blank. A graph was plotted with concentration of Itraconazole $(\mu \mathrm{g} / \mathrm{ml})$ on X-axis against absorbance $(\mathrm{nm})$ on Y-axis. The results are depicted in table.

Determination of melting point

Melting point of a compound helps in the identification of sample and to establish its purity. It can be checked by placing the sample in glass capillary tube and heated using melting point apparatus.

\section{FT-IR spectroscopy}

Fourier transform infrared (FT-IR) spectral measurements for Itraconazole, Soyalecithin, cholesterol, mixture (Itraconazole, Soyalecithin, cholesterol).and their combinations were recorded using thermo-IR 200 FTIR spectrophotometer. Potassium bromide pellet method was employed. The pure drug and their mixtures were finely ground with $\mathrm{KBr}$ to prepare the pellets under a hydraulic pressure of 600 psi and back ground spectrum was collected under identical conditions. Each spectrum was derived from 16 single average scans collected in the range of $4000-400 \mathrm{~cm}^{-1}$ at the spectral resolution of $2 \mathrm{~cm}^{-1}$. 


\begin{tabular}{|l|c|c|c|c|c|c|c|}
\hline \multirow{2}{*}{$\begin{array}{l}\text { S. } \\
\text { No. }\end{array}$} & Ingredients & \multicolumn{6}{|c|}{ Formulation codes } \\
\cline { 2 - 8 } & & IPN1 & IPN2 & IPN3 & IPN4 & IPN5 & IPN6 \\
\hline 1. & Itraconazole & 200 & 200 & 200 & 200 & 200 & 200 \\
\hline 2. & Cholesterol & 200 & 200 & 200 & 200 & 200 & 200 \\
\hline 3. & Soya lecithin & 900 & 900 & 1200 & 1200 & 1800 & 1800 \\
\hline 4. & Propylene glycol mono caprylate & 1800 & - & 1800 & - & - & - \\
\hline 5. & Glyceryl Monolinoleate & - & 1800 & - & 1800 & - & - \\
\hline 6. & Tween 20 & - & - & - & - & 1800 & - \\
\hline 7. & Span20 & - & - & - & - & - & 1800 \\
\hline 8. & Alcohol & $2.4 \mathrm{ml}$ & $2.4 \mathrm{ml}$ & $2.4 \mathrm{ml}$ & $2.4 \mathrm{ml}$ & $2.4 \mathrm{ml}$ & $2.4 \mathrm{ml}$ \\
\hline 9. & Phosphate buffer $\mathrm{P}^{\mathrm{H}} 7.4$ & $1.4 \mathrm{ml}$ & $1.4 \mathrm{ml}$ & $1.4 \mathrm{ml}$ & $1.4 \mathrm{ml}$ & $1.4 \mathrm{ml}$ & $1.4 \mathrm{ml}$ \\
\hline
\end{tabular}

Table 1: Composition of different formulations of Proniosomes.

Preparation of proniosomes - co acervation phase separation method

Proniosomal gels can be prepared by this method which comprises of surfactant, lipid and drug in a wide mouthed glass vial along with small amount of alcohol in it. The mixture is warmed over water bath at $60-70^{\circ} \mathrm{C}$ for $5 \mathrm{~min}$ until the surfactant mixture is dissolved completely. Then the aqueous phase is added to the above vial and warmed still a clear solution is formed which is then converted into proniosomal gel on cooling. After hydration of proniosomes they are converted to uniformly sized niosomes.

Evaluation studies

\section{Entrapment efficiency}

The IPN formulation was taken in a test tube and reconstituted with $10 \mathrm{~mL}$ of PBS (pH 7.4). This aqueous solution was sonicated in a sonicator bath for $10 \mathrm{~min}$. The drug containing proniosomes were separated from the unentrapped drug by centrifugation at $25,000 \mathrm{rpm}$ for $30 \mathrm{~min}$ at $20^{\circ} \mathrm{C}$. The supernatant was removed and diluted with PBS. The drug concentration in the resulting solution was assayed by the UV spectroscopic method. The percentage of drug encapsulation was calculated by using the following equation.

$\mathrm{EP}(\%)=[(\mathrm{Ct}-\mathrm{Cr}) / \mathrm{Ct}] \times 100$

Where EP is the encapsulation percentage,

$\mathrm{Ct}$ is the concentration of total drug.

$\mathrm{Cr}$ is the concentration of free drug.
In vitro drug release studies

The in vitro drug release studies of itraconazole proniosomal dispersion formulations was determined by containing phosphate buffer $\mathrm{pH} 7.4$ by using dialysis membrane was constantly stirred at $50 \mathrm{rpm}$ and the temperature was maintained at $37 \pm 2{ }^{\circ} \mathrm{C}$. The aliquots were withdrawn at 1, 2, 3, 4, 5, 6, 7 and $8 \mathrm{~h}$. Soon after withdrawal of the aliquots, the receptor compartment was replaced with fresh buffer solution to maintain sink conditions. The samples were analyzed by using a UV-visible spectrophotometer at $248 \mathrm{~nm}$.

\section{Drug content}

A specific quantity (100 $\mathrm{mg}$ ) of proniosomal dispersion was taken and dissolved in $100 \mathrm{ml}$ of phosphate buffer of $\mathrm{pH} 7.4$. The volumetric flask containing dispersion was shaken for $2 \mathrm{hr}$ on mechanical shaker in order to get complete solubility of drug. This solution was filtered and estimated spectrophotometrically at 248 nm using phosphate buffer ( $\mathrm{pH}$ 7.4) as blank.

\section{Drug release kinetics}

As a model-independent approach, comparison of the time taken for the given proportion of the active drug to be dissolved in the dissolution medium and figures such as $\mathrm{T}_{50}$ and $\mathrm{T}_{90}$ calculated by taking the time points of $50 \%$ and $90 \%$ of the drug dissolved and another parameter dissolution efficiency (DE) suggested by Khan were employed. DE is defined as the area under the dissolution curve up to the time ' $t$ ' expressed as a percentage of the area of the rectangle described by $100 \%$ dissolution in the same time. 
Dissolution Efficiency (DE) $=\left(\frac{\int_{0}^{t} y \cdot d}{y_{100} \cdot t}\right) 100$

The dissolution efficiency can have a range of values depending on the time interval chosen. In any case constant time intervals should be chosen for comparison. For example, the index $\mathrm{DE}_{30}$ would relate to the dissolution of the drug from a particular formulation after 30 minutes could only be compared with $\mathrm{DE}_{30}$ of other formulations. Summation of the drug dissolution data into a single figure DE enables ready comparison to be made between a large numbers of formulations.

As a model-dependent approach to describe the mechanisms and also the release kinetics, dissolution data were fitted to popular release models, which have been described as follows.

\section{Zero order kinetics}

Dissolution of drug from a dosage form that do not disaggregate and release the drug slowly that is where drug release rate is independent of its concentration can be represented as follows.

Where,

$A_{0}$ is initial amount of drug in the dosage form,

$A_{t}$ is the amount of drug in the dosage form at time ' $t$ ',

$\mathrm{k}_{0}$ is the zero order release constant.

To study the release kinetics, in-vitro drug release studies were plotted as cumulative amount of drug release Vs time. This relation can be used to determine the drug dissolution of various types of modified release dosage forms e.g. some transdermal systems, matrix tablets with low soluble drugs, coated forms, and osmotic systems etc. The dosage forms following this profile, release the same amount of drug by unit time and it is the ideal method of drug release in order to achieve a prolonged pharmacological action.

\section{First order kinetics}

The first order kinetics was first applied for drug dissolution studies by Gibaldi and Feldman in 1967 and later by Wagner in 1969. In this case the drug release rate is concentration dependent and this can be depicted in decimal logarithm as follows.
Where,

$\mathrm{C}_{\mathrm{t}}$ is the amount of drug released in time ' $\mathrm{t}$ ',

$\mathrm{C}_{0}$ is the initial amount of the drug in the solution,

$\mathrm{K}_{1}$ is the first order release constant.

To study the release kinetics, the data obtained are plotted as log cumulative percentage of drug remaining Vs time. Example for the dosage form follows this profile such as those containing water soluble drug in a porous matrices release the drug that is proportional to the amount of drug released by unit time diminish.

\section{Hixon-Crowell cube-root model}

To evaluate the drug release with changes in the surface area and the diameter of the particles, Hixon-Crowell in 1931 recognized that the particle regular area is proportional to the cubic root of its volume and designed an equation as follows.

Where,

$\mathrm{W}_{0}$ is the initial amount of drug in the dosage form,

$\mathrm{W}_{\mathrm{t}}$ is the remaining amount of drug in the dosage form at time ' $\mathrm{t}$ '

$\mathrm{K}_{\mathrm{s}}$ is a constant incorporating the surface volume relation.

To study the release kinetics, cube root of drug percentage remaining in matrix data Vs time is plotted. This model applies to pharmaceutical dosage forms, where the dissolution occurs in planes that are parallel to the surface area of the drug. The geometrical shape of the dosage form diminishes proportionally all the time. This model is used by assuming that release rate is limited by the drug particles dissolution rate and not by the diffusion.

\section{Higuchi model}

Higuchi in 1961 developed a model to study the release of water soluble and low soluble drugs incorporated in semisolid and solid matrices. To study the dissolution from a planer system having a homogeneous matrix the relation obtained was follows.

Where,

$f_{t}$ is the fraction of drug released in time ' $t$ ' per unit area,

$\mathrm{A}, \mathrm{C}$ is the initial drug concentrations,

$\mathrm{C}_{\mathrm{s}}$ is the drug solubility in the matrix media, 
D is the diffusivity of drug molecules in the matrix substance.

In general, Higuchi model can be simplified as,

Where,

$\mathrm{K}_{\mathrm{H}}$ is the Higuchi dissolution constant.

To study the release kinetics, data obtained were plotted as cumulative percentage drug release Vs square root of time. Drug dissolution from some modified release dosage forms like some transdermal systems and matrix tablets with water soluble drugs follows the above relationship.

\section{Korsmeyer-Peppas model}

In 1983, Korsmeyer developed a simple and semi-empiric model, when diffusion is the main drug release mechanism, relating exponentially the drug release to the elapsed time $(\mathrm{t})$.

Where,

$\mathrm{n}$ is the diffusion exponent for the drug release,

$\mathrm{t}$ is the release time,

$\mathrm{K}$ is the release rate constant

$\mathrm{A}_{\mathrm{t}} / \mathrm{A}_{\infty}$ is the fraction of drug release at time ' $\mathrm{t}$ ' (Suvakanta dash, 2013, Chime Salome, 2003).

\section{Characterization of proniosomes}

\section{Optical microscopy}

A small quantity of IPN was taken and suspended in $10 \mathrm{~mL}$ of PBS ( $\mathrm{pH}$ 7.4). The dispersion of proniosome was manually shaken for few seconds so that lumps of proniosomes are disintegrated into individual proniosomes. A drop of the dispersion was placed onto the slide and examined under the microscope. At 100× magnification, circular vesicle bodies were observed with uniform small size.

\section{Zeta potential measurements}

Zeta potential measurements were performed by PCS using the Malvern Zetasizer Nano ZS (Malvern Instruments). Before measurement, proniosomal gel formulations were hydrated and samples were appropriately diluted with distilled water.

\section{SEM (Scanning electron microscopy)}

Scanning electron microscopy (SEM) was conducted to characterize the surface morphology of the niosomes including the controls (empty vesicles). One drop of niosomal system was mounted on clear glass stub, air dried and sputter coated with gold palladium (Au/Pd) using a vacuum evaporator (Edwards) and examined using a scanning electron microscope JSM-5510 (Jeol Ltd., Tokyo, Japan) equipped with a digital camera, at 15 or $20 \mathrm{kV}$ accelerating voltage.

\section{Assessment of in vitro anti fungal activity}

Itraconazole has a broader spectrum of activity it is active against Aspergillus infective organisms and other species at dose level of $200 \mathrm{mg}$. It is also licensed for use in blastomycosis, sporotrichosis, histoplasmosis, and onychomycosis. To determine the antifungal activity of itraconazole saubouraud's glucose agar medium was used as growth medium for fungal culture and the fungal activity was tested against Candida albicans.

\section{Preparation of Sabouraud's glucose agar (SGA) medium}

SGA (glucose $40 \mathrm{~g}$, peptone $10 \mathrm{~g}$, agar $20 \mathrm{~g}$ and distilled water $1 \mathrm{ml}$ ) was prepared according to the method described in the literature. Glucose and peptone were dissolved in distilled water and the $\mathrm{pH}$ adjusted to 5.4. To this solution agar was added and it was melted on a water bath and the $\mathrm{pH}$ checked again and poured into sterile petri plates. The media were sterilized in an autoclave at $115^{\circ} \mathrm{C}$ for 20 min (Timothy, 2012).

\section{Inoculation and examination of the cultures}

Inoculation and examination of the growth of the fungi were carried out as per a widely used method. CA extract of $0.14 \mathrm{ml}$, ethosomal dispersion of $37 \mathrm{ml}$ and $0.8 \mathrm{~g}$ of ethosomal gel were separately incorporated into the molten SGA medium. The medium was then poured into sterile Petri plates, allowed to solidify and dried before use. The fungi were loaded onto SGA medium and sub cultured periodically. One-week-old subcultures of these fungi were used for inoculation. The fungal cultures were inoculated using a straight or hooked nichrome wire and the inocula pressed into the surface of the solidified medium. The fungal colonies were developed from a single inoculation into the solidified medium. 
The inoculated plates of contaminant fungal cultures and dermatophytes fungal cultures were incubated at $27 \pm 1^{\circ} \mathrm{C}$ and $22 \pm 1^{\circ} \mathrm{C}$, respectively, for 5 days. Growth became visible ranging from $24 \mathrm{~h}$ to 2-3 weeks. The inoculated plates were examined daily until fungal growth inhibition is visible (Palanichamy, 1990).

\section{Preparation of Proniosomal gel}

To prepare Proniosomal gel Methyl paraben and Propyl paraben were dissolved in water. Gelling agent i.e. carbopol 934 was added to it and stirred continuously till it got swollen completely. Then add $5 \mathrm{ml}$ of proniosomal dispersion. Triethanolamine was slowly added to the dispersion with continuous stirring Stirred for $15 \mathrm{~min}$ continuously till a uniform gel was formed which resulted in a stiff gel.

\begin{tabular}{|c|c|c|c|c|}
\hline $\begin{array}{c}\text { Carbopol } \\
\mathbf{9 3 4}\end{array}$ & $\begin{array}{c}\text { Methyl } \\
\text { paraben } \\
\text { (g) }\end{array}$ & $\begin{array}{c}\text { Propyl } \\
\text { paraben } \\
\text { (g) }\end{array}$ & $\begin{array}{c}\text { Proniosomal } \\
\text { dispersion }\end{array}$ & $\begin{array}{c}\text { Triethanol- } \\
\text { amine }\end{array}$ \\
\hline $1 \% \mathrm{w} / \mathrm{v}$ & 0.020 & 0.002 & $5 \mathrm{ml}$ & 2.0 \\
\hline
\end{tabular}

Table 2: Composition of Proniosomal gel.

Evaluation studies proniosomal gel

Physical appearance and Homogeneity

The physical appearance and homogeneity of the prepared gels were tested by visual observations after the gels have been set in the container. They were tested for their appearance and presence of any aggregates.

\section{Clarity}

The clarity of various formulations was determined by visual inspection under black and white background and it was graded as follows; turbid: +, clear: ++, very clear (glassy): +++.

\section{pH Determination}

$1.0 \mathrm{~g}$ gel was accurately weighed and dispersed in $100 \mathrm{ml}$ purified water. The $p \mathrm{H}$ of the dispersion was measured using digital $\mathrm{pH}$ meter, which was calibrated before use with standard buffer solution at 4.0, 7.0 and 9.0. The measurements of $p H$ were done in triplicate and average values were calculated.

Viscosity
Brookfield digital viscometer was used for the determination of viscosity and rheological properties of itraconazole proniosomal gel using spindle noT-96. The viscosity of gel was measured at different angular velocities at a temperature of $37^{\circ}$ C.Atypical run comprised changing of the angular velocity from 0.3 to $2.5 \mathrm{rpm}$. The averages of two readings were used to calculate the viscosity.

\section{Spreadability}

One of the criteria for a topical formulation to meet the ideal qualities is that it should possess good spreadability. It is the term expressed to denote the extent of area to which formulation readily spreads on application to skin or affected part. The therapeutic efficacy of a formulation also depends upon its spreading value. To determine the spreadability of formulation The spreadability of the gel was determined using the following technique: $0.5 \mathrm{~g}$ gel was placed within a circle of $1 \mathrm{~cm}$ diameter pre marked on a glass plate over which a second glass plate was placed. A weight of $500 \mathrm{~g}$ was allowed to rest on the upper glass plate for $5 \mathrm{~min}$. The increase in the diameter due to spreading of the gels was noted.

\section{Extrudability}

To determine extrudability a closed collapsible tube containing formulation was pressed firmly at the crimped end. When the cap was removed, formulation extruded until the pressure dissipated. Weight in grams required to extrude a $0.5 \mathrm{~cm}$ ribbon of the formulation in $10 \mathrm{sec}$ was determined. The average extrusion pressure in g was reported.

\section{In vitro drug diffusion studies}

In vitro release studies were performed using modified Franz diffusion cell. Proniosomal gel of different formulations was placed in the donor compartment and the top of the donor compartment was covered with paraffin film. $200 \mathrm{ml}$ of phosphate buffer $\mathrm{pH} 7.4$ was used as receptor medium to ensure a sink condition. The receptor compartment was maintained at $37^{\circ} \mathrm{C}$ and stirred by a magnetic bar at $600 \mathrm{rpm}$. The donor compartment was separated from the receptor compartment by cellulose dialyzing membrane which was soaked in the receptor medium overnight. At predetermined time intervals $(15,30,45,60,120,180,240,300,360,420 \mathrm{~min}$.) $1 \mathrm{ml}$ aliquots were withdrawn from the sampling port and were replaced with an equal volume of fresh solvent mixture to maintain constant volume. The samples were analyzed spectrophotometri- 
cally at $248 \mathrm{~nm}$. In reference with the constructed calibration curve (0.999). For each formula, drug release was studied in triplicate and the cumulative amount of drug released was determined.

Results and Discussion

Pre - formulation studies

\section{Calibration curve of itraconazole}

In the present study, analytical method obeyed the beer- lamberts law in the concentration range of $2-10 \mu \mathrm{g} / \mathrm{ml}$ and was suitable for the estimation of Itraconazole. Using phosphate buffer pH7.4. The value of or (correlation coefficient) for the linear regression equation was found to be 0.999 . Which indicates a positive correla-

\begin{tabular}{|c|c|c|}
\hline S. No. & Concentration $($ in $\mu \mathrm{g} / \mathbf{m l})$ & Absorbance \\
\hline 1. & 2 & $0.194 \pm 0.02$ \\
\hline 2. & 4 & $0.367 \pm 0.08$ \\
\hline 3. & 6 & $0.545 \pm 0.143$ \\
\hline 4. & 8 & $0.723 \pm 0.02$ \\
\hline 5. & 10 & $0.892 \pm 0.02$ \\
\hline
\end{tabular}

Table 3: Calibration curve data of Itraconazole using phosphate buffer $\mathrm{pH} 7.4$.

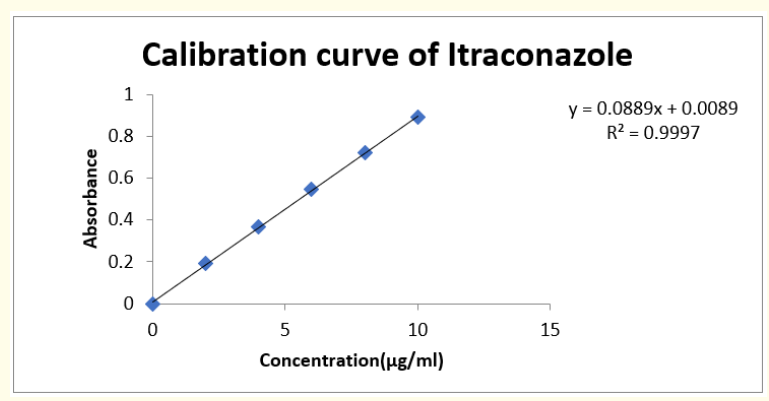

Figure 2: Standard curve of Itraconazole in phosphate buffer $\mathrm{pH}$ 7.4 .

tion between the concentration of drug and the corresponding absorbance values. The linear equations for all the calibration curves followed with the intercept of 0 and slightly above 0 . The linear regression equations were used for the estimation of selected drug from phosphate buffer $\mathrm{pH} 7.4$.
Melting point

Melting point of the pure Itraconazole was found to be $166.3{ }^{\circ} \mathrm{C}$ which is within the range of $166.2166 .5^{\circ} \mathrm{C}$ as reported in literature, thus indicating purity of the drug sample.

\section{FT-IR spectroscopy}

The physicochemical compatibility of the drug and the polymer was established through FT-IR studies. The FT-IR spectra of Itraconazole observed peaks are $2967.95 \mathrm{~cm}^{-1}, 2823.68 \mathrm{~cm}^{1}$, $1697.03 \mathrm{~cm}^{-1}, 1521.06 \mathrm{~cm}^{-1}, 1453.00 \mathrm{~cm}^{-1}, 1331.15 \mathrm{~cm}^{-1}, 1331.55$ $\mathrm{cm}^{-1}, 1272.87 \mathrm{~cm}^{-1}, 1043.54 \mathrm{~cm}^{-1}, 821.95 \mathrm{~cm}^{-1}, 736.95 \mathrm{~cm}^{-1}$. Indicating the $\mathrm{C}-\mathrm{H}_{2}$ (symmetric stretching), $\mathrm{C}=\mathrm{O}$ and $\mathrm{C}=\mathrm{N}$ (Streching), C-C (streching), $\mathrm{C}=\mathrm{C}$ (streching), C-O (Streching), C-N (Aromatic $1^{0}$

\begin{tabular}{|c|c|c|c|c|c|c|}
\hline S. & Func- & Charac- & \multicolumn{4}{|c|}{ Observed peaks } \\
\cline { 4 - 7 } No & tional & teristic & Itracon- & Choles- & Soya \\
peaks & azole & $\begin{array}{c}\text { Physical } \\
\text { terol }\end{array}$ & $\begin{array}{c}\text { lecithin } \\
\text { Mixture }\end{array}$ \\
\hline 1. & C=C & $\begin{array}{c}1800- \\
1600\end{array}$ & 1453 & 1698 & - & 1696 \\
\hline 2. & C=N & $\begin{array}{c}1600- \\
1700\end{array}$ & 1697 & - & - & - \\
\hline 3. & C=0 & $\begin{array}{c}1800- \\
1600\end{array}$ & 1697 & - & 1735 & 1696 \\
\hline 4. & C-H & $3500-$ & 2967 & 1229 & 2852 & 1460 \\
\hline 5. & & 3000 & & & & \\
\hline 6. & O-H & $1200-800$ & 1521 & 1050 & 1525 & 1509 \\
\hline
\end{tabular}

Table 4: FT-IR Interpretation of pure drug and excipients.

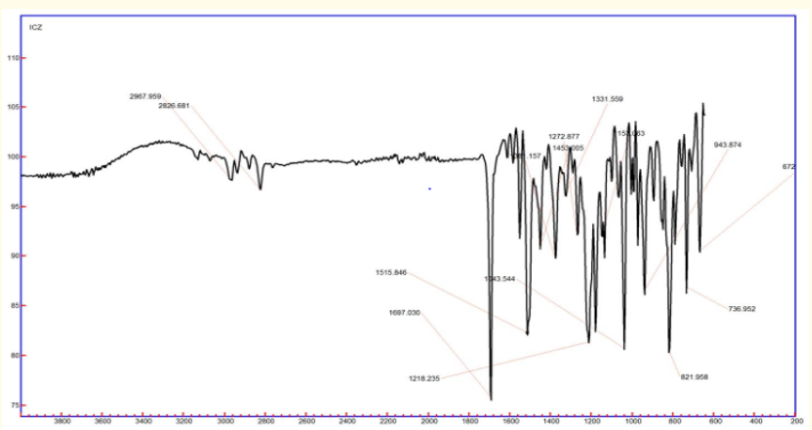

Figure 3: FT-IR Spectroscopy of Itraconazole. 


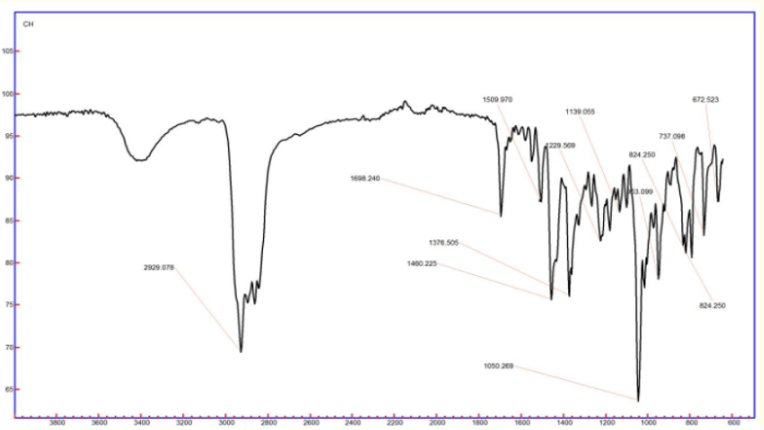

Figure 4: FT-IR Spectroscopy of cholesterol.

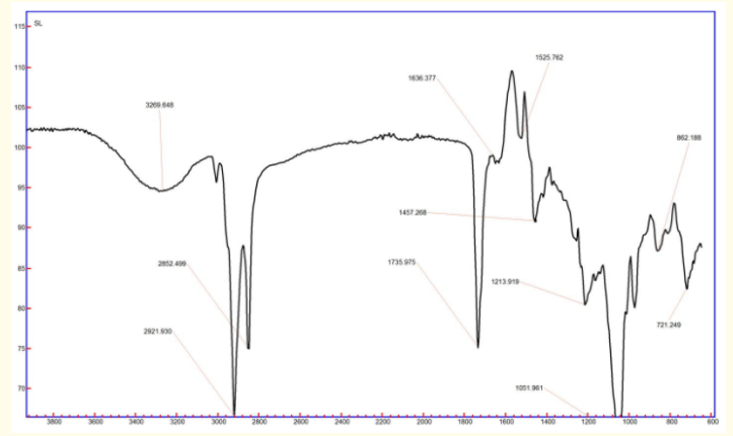

Figure 5: FT-IR Spectroscopy of Soya lecithin.

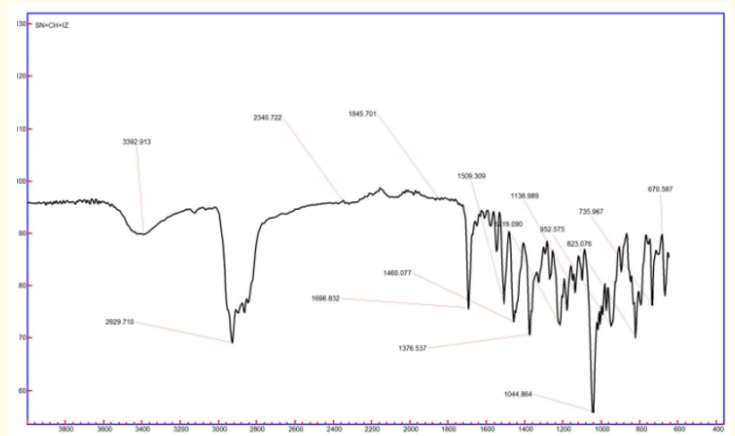

Figure 6: FT-IR Spectroscopy of mixture (Itraconazole, cholesterol, soyalecithin).

amine, C-N streching) C-N (Aromatic $2^{0}$ amine, C-N streching), N-N (Bending), $\mathrm{C}-\mathrm{Cl}$ (streching).

FT-IR spectra of soyalecithin observed peaks are $2921.93 \mathrm{~cm}^{-}$ 1, $2852.4 \mathrm{~cm}^{-1}, 1735.97 \mathrm{~cm}^{-1}, 1636.37 \mathrm{~cm}^{-1}, 1525.76 \mathrm{~cm}^{-1} 1457.26$ $\mathrm{cm}^{-1}, 1213.91 \mathrm{~cm}^{-1}, 1051.96 \mathrm{~cm}^{-1}, 1213.91 \mathrm{~cm}^{-1}$. That indicating C-H
(Methyl Asymmetric or symmetric streching), C-H(Methyl asymmetric or symmetric streching), $\mathrm{C}=\mathrm{O}$ (streching), $\mathrm{C}-\mathrm{N}$ (streching), $\mathrm{C}-\mathrm{C}$ (streching), $\mathrm{C}-\mathrm{H}($ Methylene $\mathrm{C}-\mathrm{H}($ Bending), $\mathrm{P}=\mathrm{O}$ (streching), $\mathrm{C}-$ $\mathrm{O}$ (streching).

FT-IR Spectra of cholesterol observed peaks are $2929.07 \mathrm{~cm}^{-1}$, $1698.24 \mathrm{~cm}^{-1}, 1460.22 \mathrm{~cm}^{-1} 1229.56 \mathrm{~cm}^{-1}, 1139.055 \mathrm{~cm}^{-1}, 824.850$ $\mathrm{cm}^{-1}, 737.09 \mathrm{~cm}^{-1}$. That indicating the $\mathrm{C}=\mathrm{C}$ (streching), $\mathrm{C}-\mathrm{H}$ (Aromatic $\mathrm{C}-\mathrm{H}$ in plane of bending), $\mathrm{C}-\mathrm{O}$ (streching), C-C(streching), C$\mathrm{H}$ (Aromatic $\mathrm{C}-\mathrm{H}$ out of the plane bending), $\mathrm{C}-\mathrm{H}$ (Aromatic $\mathrm{C}-\mathrm{H}$ out of the plane bending).

FT-IR Spectra of physical mixture (Itraconazole, Soyalecithin, Cholesterol) observed peaks are $3392.91 \mathrm{~cm}^{-1}, 2929.71 \mathrm{~cm}^{-1}$, $1696.83 \mathrm{~cm}^{-1}, 1509.309 \mathrm{~cm}^{1}, 1460.07 \mathrm{~cm}^{-1}, 1376.53 \mathrm{~cm}^{-1}, 1138.98$ $\mathrm{cm}^{-1}, 1044.86 \mathrm{~cm}^{-1}, 823.07 \mathrm{~cm}^{-1}$. That indicating $\mathrm{OH}$ (streching), C$\mathrm{H}$ (Methyl C-H asymmetric or symmetricstreching), $\mathrm{C}=\mathrm{C}$ (streching), $\mathrm{C}=\mathrm{O}$ (streching), $\mathrm{C}-\mathrm{C}($ streching), $\mathrm{C} \mathrm{H}($ Methylene- $\mathrm{H}$ bending), $\mathrm{C}$ $\mathrm{N}$ (streching), $\mathrm{N}-\mathrm{N}$ (bending), $\mathrm{C}-\mathrm{C}$ (streching), $\mathrm{P}=\mathrm{O}$ (streching), $\mathrm{C}$ $\mathrm{O}$ (streching), C-Cl(streching).

FT-IR studies reveals that there no physical interaction between drug and physical mixture.

\section{Entrapment efficiency}

The niosomes formed from Span 20 containing proniosomal gel has showed better entrapment compared to that of other surfactants. This is due to that entrapment efficiency depends on the structure of the surfactant. Longer the saturated alkyl chain of the

\begin{tabular}{|c|c|c|}
\hline S. No. & Formulation code & \% Entrapment efficiency $(\mathbf{n}=\mathbf{3})$ \\
\hline 1. & IPN1 & $62.05 \pm 0.215$ \\
\hline 2. & IPN2 & $65.07 \pm 0.161$ \\
\hline 3. & IPN3 & $68.10 \pm 0.265$ \\
\hline 4. & IPN4 & $70.79 \pm 0.129$ \\
\hline 5. & IPN5 & $73.31 \pm 0.176$ \\
\hline 6. & IPN6 & $76.68 \pm 0.186$ \\
\hline
\end{tabular}

Table 5: Entrapment efficiency of itraconazole proniosomal formulations.

surfactant, greater is the entrapment efficiency. Tween20, Propylene glycol Monocaprylate, Glyceryl monolieate possess unsaturated alkyl chain which made the chains bend and more permeable when it forms membrane which ultimately leads to lowest entrapment efficiency. It suggests that the alkyl chain of surfactant is a crucial factor in entrapment efficiency and saturated chain produces higher entrapment compared to unsaturated chain. Effect of 
soya lecithin on entrapment efficiency was not significant.

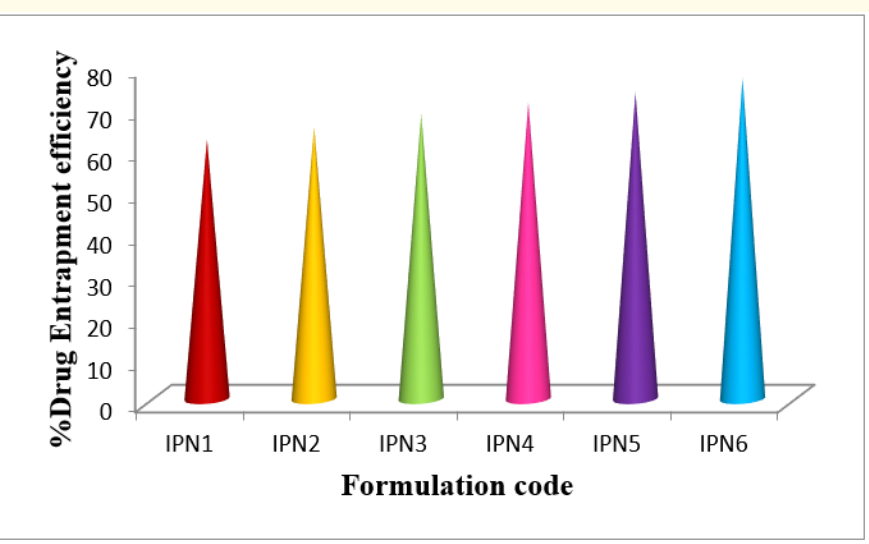

Figure 7: \% Drug entrapment efficiency of Itraconazole proniosomal Formulations.

\section{In vitro dissolution studies}

Niosomes prepared using Span 20 showed a higher release rate than those prepared using non-ionic surfactants, Tween20 Propylene glycol Monocaprylate and Glyceryl Monolinoleate. Tween20, Propylene glycol mono caprylate and Glyceryl Monolinoleate possess lower phase transition temperatures and form less permeable rigid bilayers than Span 20, which forms a more permeable fluid bilayer. Based on the in vitro release results, Span 20 higher phase transition temperature (showing higher release rates) was selected for further studies.

The maximum percentage drug release was found to be $90.10 \%$ which was exhibited by formulation containing span 20 .

Drug content

\begin{tabular}{|c|c|c|c|c|c|c|c|c|}
\hline S. & Time & \multicolumn{7}{|c|}{ \% drug release (n = 3) } \\
\cline { 5 - 9 } No. & $(\mathbf{m i n})$ & Pure Drug & IPN1 & IPN2 & IPN3 & IPN4 & IPN5 & IPN6 \\
\hline 1. & 15 & $7.47 \pm 0.11$ & $13.62 \pm 0.156$ & $16.76 \pm 0.103$ & $18.33 \pm 0.145$ & $19.38 \pm 0.236$ & $20.21 \pm 0.169$ & $21.47 \pm 0.118$ \\
\hline 2. & 30 & $8.52 \pm 0.134$ & $22.52 \pm 0.158$ & $24.05 \pm 0.126$ & $23.05 \pm 0.324$ & $25.57 \pm 0.234$ & $26.19 \pm 0.245$ & $27.76 \pm 0.239$ \\
\hline 3. & 45 & $9.27 \pm 0.165$ & $29.33 \pm 0.186$ & $28.81 \pm 0.325$ & $30.38 \pm 0.244$ & $32.18 \pm 0.356$ & $33.52 \pm 0.179$ & $34.54 \pm 0.264$ \\
\hline 4. & 60 & $10.11 \pm 0.170$ & $35.15 \pm 0.234$ & $36.31 \pm 0.265$ & $37.24 \pm 0.136$ & $38.08 \pm 0.536$ & $40.37 \pm 0.396$ & $42.15 \pm 0.357$ \\
\hline 5. & 120 & $12.10 \pm 0.212$ & $1.25 \pm 0.246$ & $46.06 \pm 0.456$ & $47.69 \pm 0.326$ & $48.12 \pm 0.267$ & $49.51 \pm 0.345$ & $50.29 \pm 0.362$ \\
\hline 6. & 180 & $14.45 \pm 0.254$ & $47.75 \pm 0.310$ & $53.18 \pm 0.247$ & $54.17 \pm 0.279$ & $55.25 \pm 0.369$ & $56.35 \pm 0.222$ & $58.32 \pm 0.265$ \\
\hline 7. & 240 & $15.19 \pm 0.214$ & $52.18 \pm 0.349$ & $61.30 \pm 0.261$ & $62.48 \pm 0.397$ & $65.26 \pm 0.410$ & $66.29 \pm 0.364$ & $68.34 \pm 0.321$ \\
\hline 8. & 300 & $16.76 \pm 0.261$ & $59.23 \pm 0.245$ & $68.35 \pm 0.341$ & $70.60 \pm 0.485$ & $75.68 \pm 0.531$ & $73.81 \pm 0.526$ & $79.05 \pm 0.363$ \\
\hline 9. & 360 & $18.33 \pm 0.109$ & $64.48 \pm 0.352$ & $73.14 \pm 0.364$ & $76.78 \pm 0.521$ & $80.56 \pm 0.287$ & $78.39 \pm 0.344$ & $87.88 \pm 0.298$ \\
\hline 10. & 420 & $20.43 \pm 0.145$ & $79.45 \pm 0.219$ & $80.16 \pm 0.420$ & $82.96 \pm 0.324$ & $84.37 \pm 0.421$ & $86.98 \pm 0.374$ & $90.10 \pm 0.112$ \\
\hline
\end{tabular}

Table 6: In vitro dissolution studies of proniosomal Formulations.

The drug content of the prepared proniosomes was performed and the maximum drug content was shown by IPN6 formulation i.e. $99.55 \%$ when compared to other five formulations (IPN1 = $77.56 \%$, IPN2 $=82.34 \%$, IPN3 = 92.65\%, IPN4 = 88.45\%, IPN5 = $95.45 \%$ ) this may be due to less loss of drug during preparation of proniosomes.

Drug release kinetics
Above all the Drug release kinetics of optimized formulation i.e.IPN6 follows the Higuchi model with Correlation coefficient $r$ value 0.975 . And thus indicating drug release kinetics in Higuchi which is the best and fit model for Itraconazole proniosomal formulations.

\section{Characterization of proniosomes}

Optical microscopy 


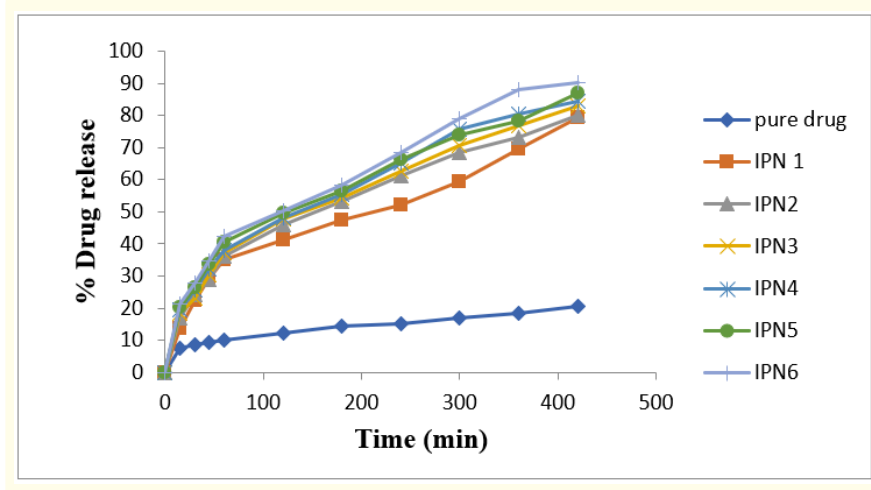

Figure 8: In vitro drug release studies of Proniosomal formulations.

\begin{tabular}{|c|c|c|}
\hline S. No. & Formulation code & \%Drug content $(\mathbf{n}=3)$ \\
\hline 1. & IPN1 & $77.56 \pm 0.123$ \\
\hline 2. & IPN2 & $82.34 \pm 0.220$ \\
\hline 3. & IPN3 & $92.65 \pm 0.114$ \\
\hline 4. & IPN4 & $88.45 \pm 0.186$ \\
\hline 5. & IPN5 & $95.45 \pm 0.102$ \\
\hline 6. & IPN6 & $99.55 \pm 0.132$ \\
\hline
\end{tabular}

Table 7: \% Drug content of Itraconazole proniosomal formulations.

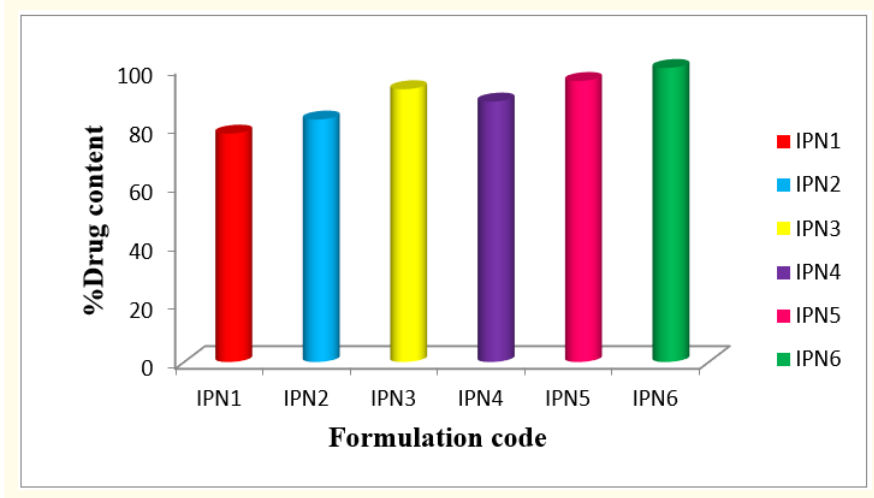

Figure 9: Drug content of Itraconazole proniosomal formulations.

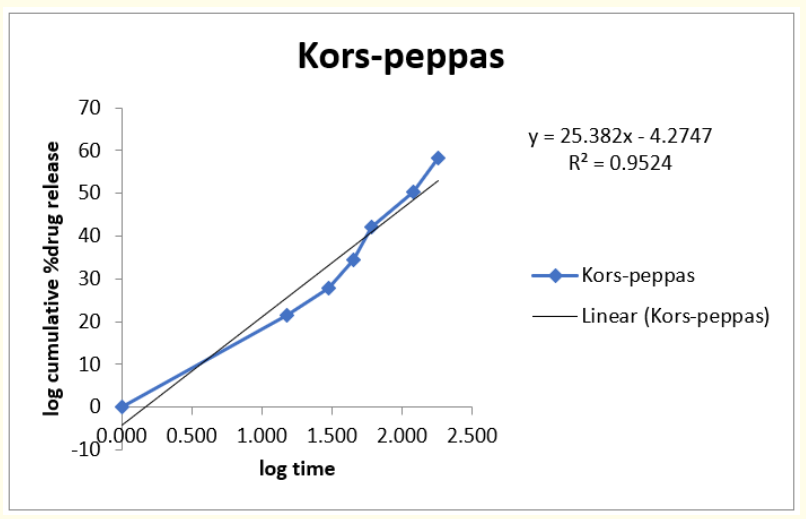

Figure 10: Drug release kinetics of kors-peppas model.

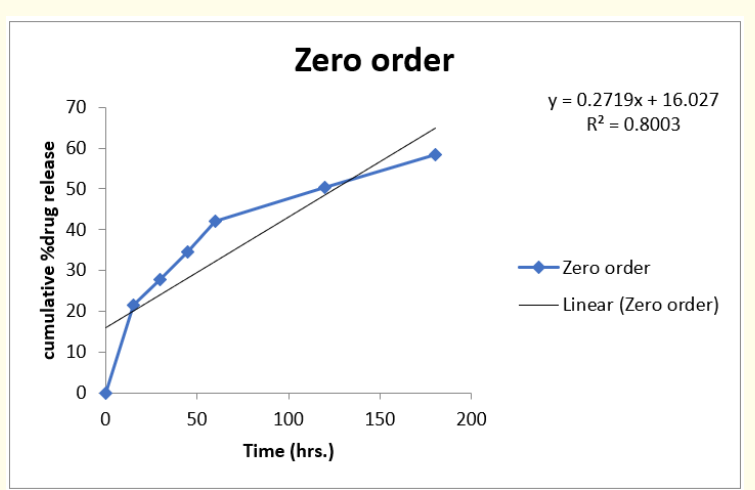

Figure 11: Drug release kinetics of Zero order.

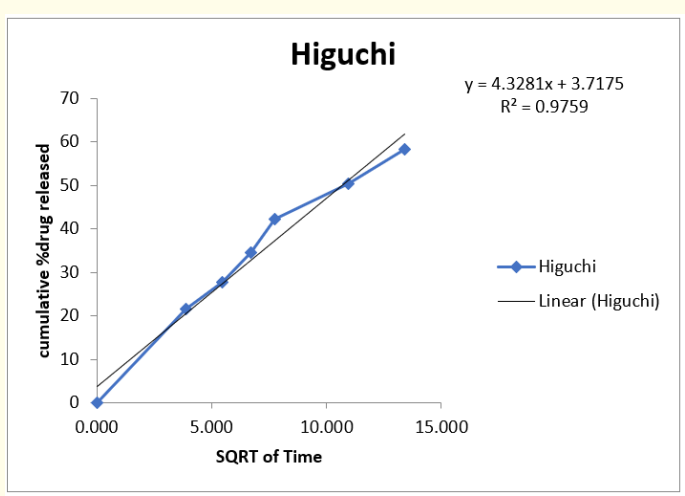

Figure 12: Drug release kinetics of Higuchi model. 


\begin{tabular}{|c|c|c|c|c|c|c|c|c|c|}
\hline $\begin{array}{l}\text { Time } \\
\text { (min) }\end{array}$ & $\begin{array}{c}\text { Cumulative\% } \\
\text { Drug release }\end{array}$ & $\begin{array}{l}\text { \% Drug } \\
\text { remaining }\end{array}$ & $\begin{array}{l}\text { Square } \\
\text { route of } \\
\text { time }\end{array}$ & $\begin{array}{l}\text { Log cum. } \\
\% \text { drug } \\
\text { remaining }\end{array}$ & $\begin{array}{l}\text { Log } \\
\text { time }\end{array}$ & $\begin{array}{l}\text { Log cum } \\
\% \text { drug } \\
\text { released }\end{array}$ & $\%$ DR & $\begin{array}{l}\text { Cube root of \% } \\
\text { drug remaining } \\
\text { g(wt) }\end{array}$ & $W_{0}-W_{t}$ \\
\hline 0 & 0 & 100 & 0.000 & 2.000 & 0.000 & 0.000 & 100 & 4.642 & 0.000 \\
\hline 15 & 12.89 & 87.11 & 3.873 & 1.940 & 1.176 & 1.110 & 12.89 & 4.433 & 0.209 \\
\hline 30 & 15.80 & 84.2 & 5.477 & 1.925 & 1.477 & 1.199 & 2.91 & 4.383 & 0.259 \\
\hline 45 & 21.18 & 78.82 & 6.708 & 1.897 & 1.653 & 1.326 & 5.38 & 4.288 & 0.354 \\
\hline 60 & 27.13 & 72.87 & 7.746 & 1.863 & 1.778 & 1.433 & 5.95 & 4.177 & 0.465 \\
\hline 120 & 35.31 & 64.69 & 10.954 & 1.811 & 2.079 & 1.548 & 8.18 & 4.014 & 0.628 \\
\hline 180 & 48.54 & 51.46 & 13.416 & 1.711 & 2.255 & 1.686 & 13.23 & 3.720 & 0.922 \\
\hline 240 & 56.59 & 43.41 & 15.492 & 1.638 & 2.380 & 1.753 & 8.05 & 3.514 & 1.128 \\
\hline 300 & 64.34 & 35.66 & 17.321 & 1.552 & 2.477 & 1.808 & 7.75 & 3.291 & 1.351 \\
\hline 360 & 73.65 & 26.35 & 18.974 & 1.421 & 2.556 & 1.867 & 9.31 & 2.976 & 1.666 \\
\hline 420 & 80.71 & 19.29 & 20.494 & 1.285 & 1.000 & 1.907 & 7.06 & 2.682 & 1.960 \\
\hline 480 & 89.23 & 10.77 & 21.909 & 1.032 & 1.000 & 1.951 & 8.52 & 2.208 & 2.434 \\
\hline
\end{tabular}

Table 8: Drug release kinetics of optimized formulations.

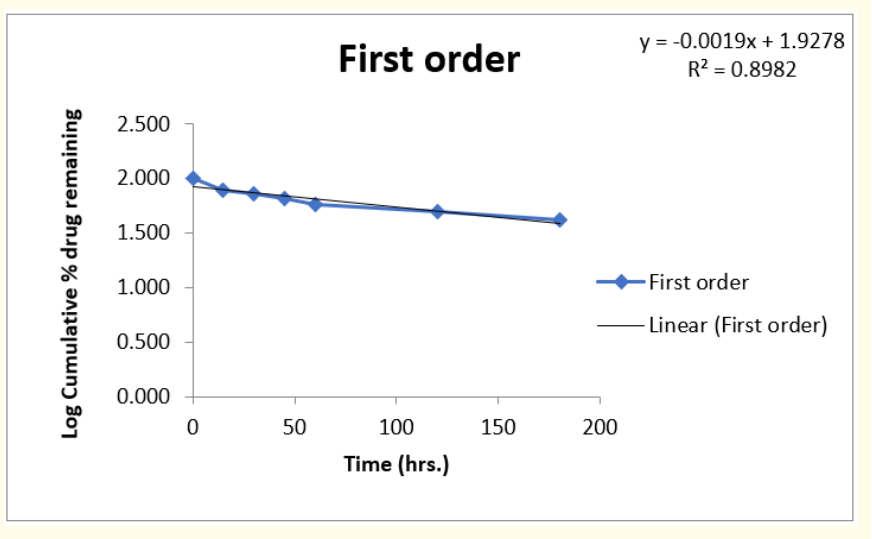

Figure 13: Drug release kinetics of first order.

Microscopic images were taken to find the vesicle morphology. From the images. it was evident that the vesicles in the proniosomes were discrete and almost spherical in shape. IPN6 and IPN5 shows discrete spherical particles with various sizes, IPN1, IPN2, IPN3, and IPN4 shows discrete particles of various size, shows discrete particles out of which majority of vesicles are spherical and some of them possess fractured/roughen edges. The colour varia-

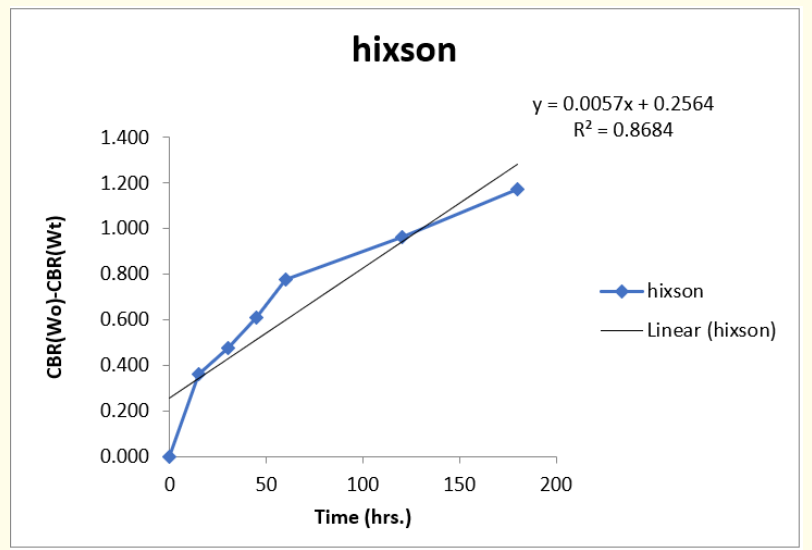

Figure 14: Drug release kinetics of Hixon crowell model.

tion of the photographs is due to the concentration variation of soya lecithin in the formulations. The difference in the size of the vesicles is purely due to the variation in the magnification.

\section{Zeta potential}




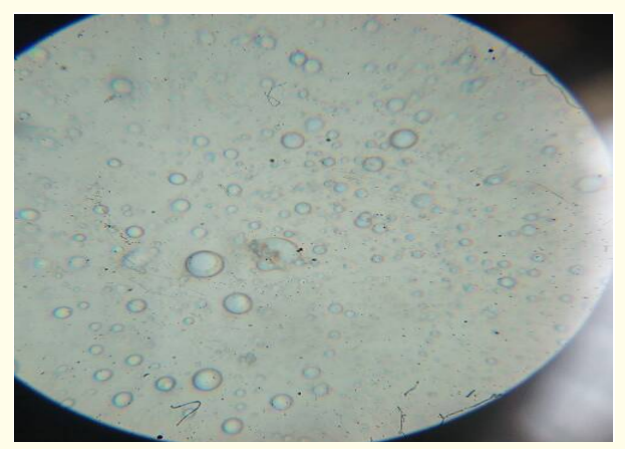

Figure 15: Microscopic image of Itraconazole proniosomal containing Span 20.

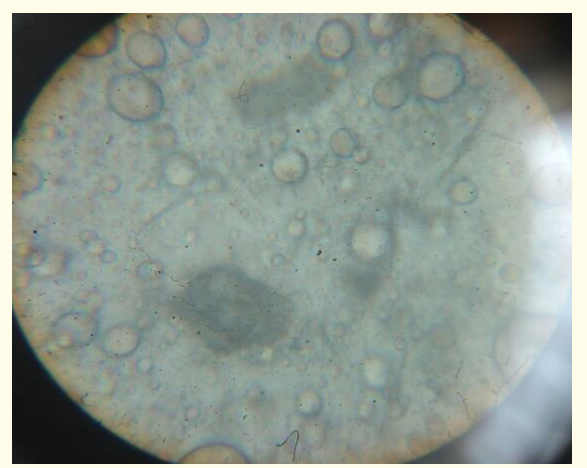

Figure 16: Microscopic images of proniosomal formulation containing Tween 20 .

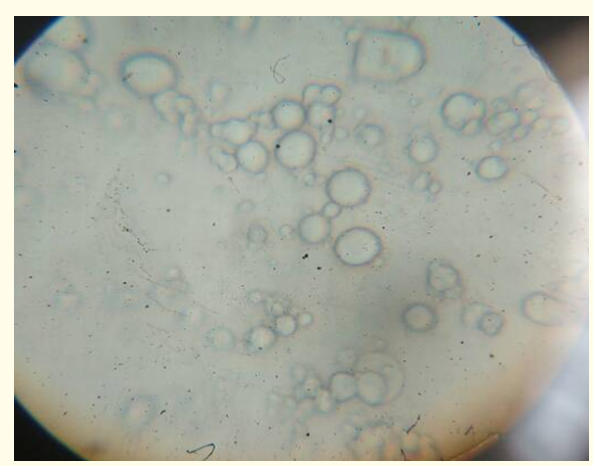

Figure 17: Microscopic images of proniosomal formulation containing Glyceryl monolinoleate.

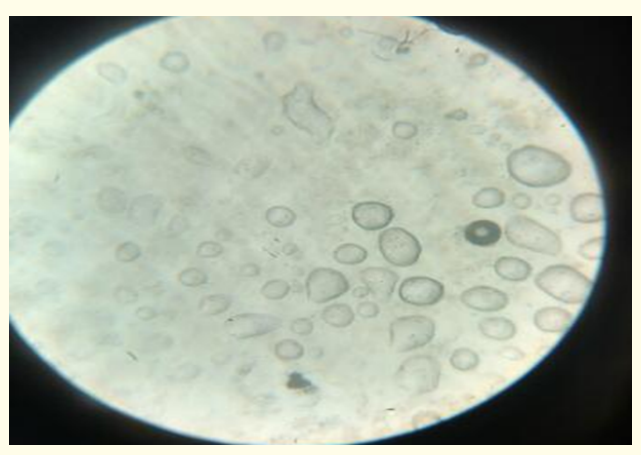

Figure 18: Microscopic images of proniosomal formulation containing propylene glycol Monocaprylate.

Measurement Results

SZ-100

201706161533000.nzt

Measurement Results

Date: Friday, June 16, 2017 3:33:30 PM

Measurement Type: Zeta Potential

Sample Name: M1

Temperature of the Holder: $25.1^{\circ} \mathrm{C}$

Dispersion Medium Viscosity: $0.893 \mathrm{mPas}$

Conductivity: $0.372 \mathrm{mS} / \mathrm{cm}$

Electrode Voltage: $3.3 \mathrm{~V}$

Calculation results

Zeta potential (mean): $41.5 \mathrm{mV}$

\begin{tabular}{|c|c|c|}
\hline Peak No. & Zeta Potential (Mean) & $\begin{array}{c}\text { Electrophoretic Mobility } \\
\text { Mean }\end{array}$ \\
\hline 1 & $-41.5 \mathrm{mV}$ & $-0.000322 \mathrm{~cm}^{2} / \mathrm{Vs}$ \\
\hline 2 & $--\mathrm{mV}$ & $---\mathrm{cm}^{2} / \mathrm{Vs}$ \\
\hline 3 & $--\mathrm{mV}$ & $---\mathrm{cm}^{2} / \mathrm{Vs}$ \\
\hline
\end{tabular}

Table a 
Electrophoretic Mobility Mean: $0.000322 \mathrm{~cm}^{2} /$ Vs.

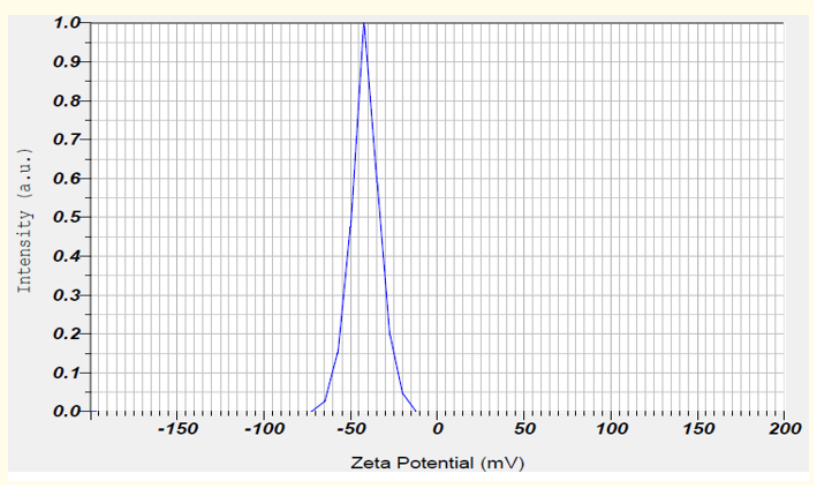

Figure 19: A graphical representation of Zeta potential of IPN6 Formulation.

\section{Zeta sizer}

SZ-100

\section{3.nsz}

Measurement Results

Date: Tuesday, June 20, 2017 5:05:13 PM

Measurement Type: Particle Size

Sample Name: M1

Scattering Angle: 173

Temperature of the Holder: $25.1^{\circ} \mathrm{C}$

Dispersion Medium Viscosity: $0.893 \mathrm{mPa} \cdot \mathrm{s}$

Transmission Intensity before Meas.: 9925

Distribution Form: Standard

Distribution Form (Dispersity): Monodisperse

Representation of Result: Scattering Light Intensity

Count Rate: 2158 kCPS.
Calculation results

\begin{tabular}{|c|c|c|c|c|}
\hline Peak No. & S. P. Area Ratio & Mean & S. D. & Mode \\
\hline 1 & 1.00 & $0.5 \mathrm{~nm}$ & $0.1 \mathrm{~nm}$ & $0.4 \mathrm{~nm}$ \\
\hline 2 & --- & $\begin{array}{c}- \\
--\mathrm{nm}\end{array}$ & $\begin{array}{c}--\mathrm{nm} \\
-\end{array}$ & $---\mathrm{nm}$ \\
\hline 3 & --- & - & $--\mathrm{nm}$ & $---\mathrm{nm}$ \\
\hline Total & 1.00 & $0.5 \mathrm{~nm}$ & $0.1 \mathrm{~nm}$ & $0.4 \mathrm{~nm}$ \\
\hline
\end{tabular}

Table b

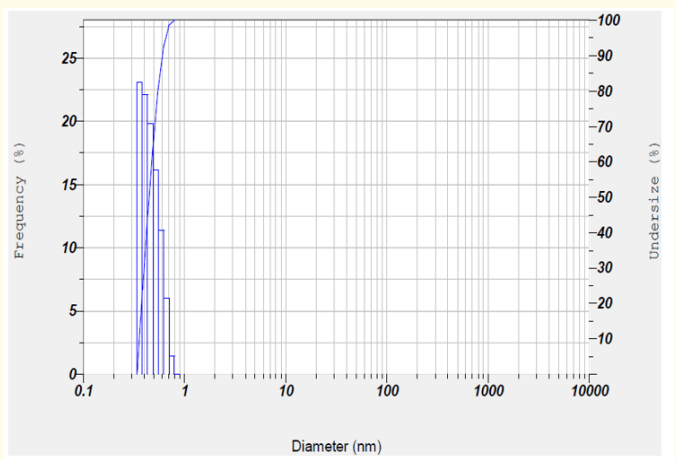

Figure 20: A graphical representation of Vesicle size of IPN6 Formulation.

The zeta potential was strongly influenced by the Non-ionic surfactants used in the formulation. The zeta potential of formulation was found to be $-41.5 \mathrm{mv}$. The ionization of surface groups produces surface charge. Physiologic surfactants are non ionic surfactants and upon ionization it produces $\mathrm{P}^{\mathrm{H}}$ dependent net surface charge.

The mean vesicle size of Itraconazole loaded optimized proniosome formulation was found to be $0.5 \mathrm{~nm}$.

\section{Scanning electron microscopy}

Results of scanning electron microscopic study of optimized IPN6 proniosomal formulations are shown in figure. Most of the vesicles are well identified, irregular spherical shape.

\section{Assessment of in vitro anti fungal activity}

Anti fungal screening studies were performed for Itraconazole proniosomal gel against Candida albicans. The results of this study 


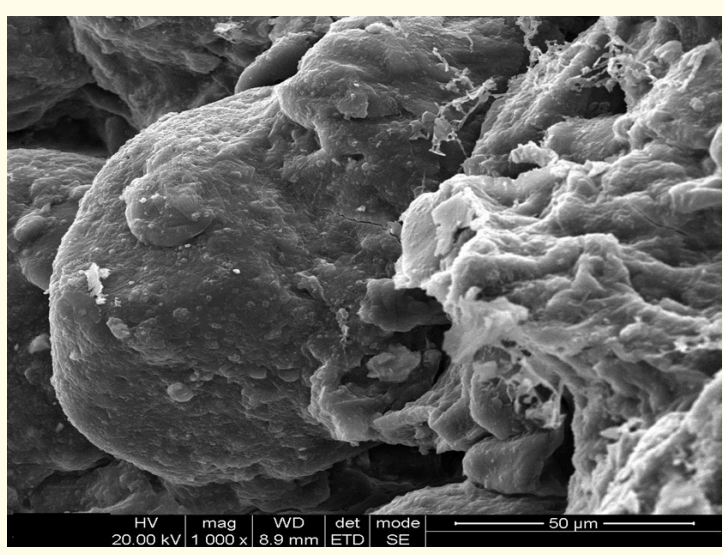

Figure 21: Scanning electron microscopic image of optimized formulation.

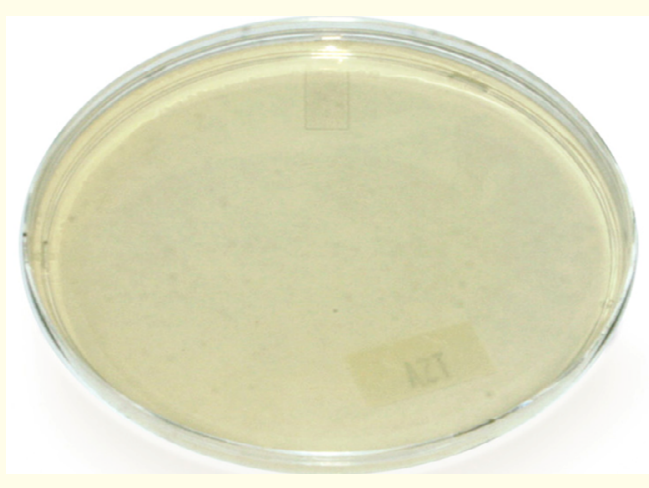

Figure 22: Sabouraud's glucose agar medium.

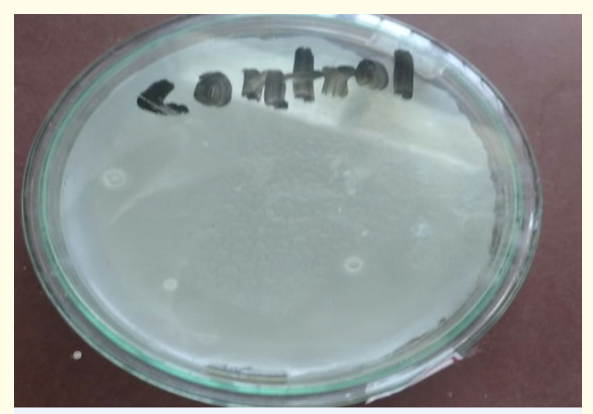

Figure 23: Representative growth of Candida albicans on agar medium.

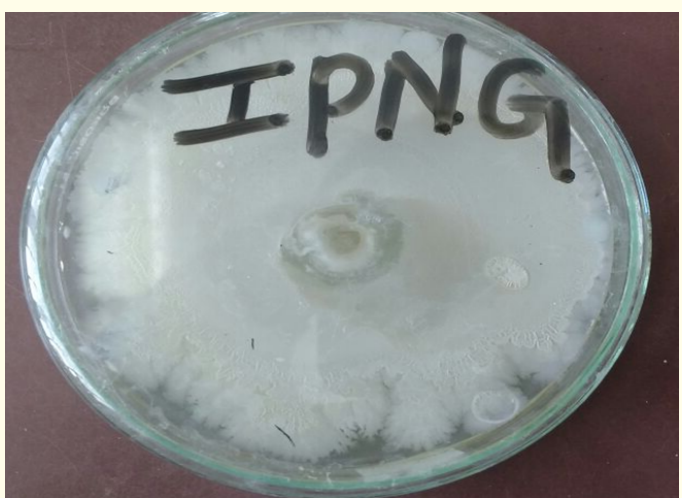

Figure 24: Zone of inhibition of fungal strain by Proniosomal gel.

revealed that the proniosomal gel is efficient in inhibiting the growth of fungal species. The zone of inhibition was found to be 1.5 $\mathrm{cm}$ after 5 days of incubation.

Evaluation of proniosomal gel

\begin{tabular}{|c|c|c|c|c|c|}
\hline $\begin{array}{c}\text { Formu- } \\
\text { lation }\end{array}$ & Color & $\begin{array}{c}\text { Homo- } \\
\text { geneity }\end{array}$ & $\begin{array}{c}\text { Phase } \\
\text { separa- } \\
\text { tion }\end{array}$ & $\begin{array}{c}\text { Occlu- } \\
\text { siveness }\end{array}$ & $\begin{array}{c}\text { Wash- } \\
\text { ability }\end{array}$ \\
\hline IPN6 & White & $\begin{array}{c}\text { Homog- } \\
\text { enous }\end{array}$ & No & Yes & $\begin{array}{c}\text { Wash- } \\
\text { able }\end{array}$ \\
\hline
\end{tabular}

Table 9: Physical evaluation of Proniosomal gel.

The Itraconazole proniosomal gel formulation has showed no phase separation, good Occlusiveness and washability. And white color and homogeneity due to more amount of unentrapped drug.

pH

The $\mathrm{pH}$ of optimized proniosomal formulation were found to be 6.6 that suits the skin $\mathrm{pH}$, indicating skin compatibility.

\section{Clarity}

All gels were found to be transparent and were free from presence of particles.

\section{Spreadability}

Spreadability diameter for different formulations showed good spreadability i.e. gel is easily spreadable. 
Extrudability

The extrudability of formulations was found to be good.

Viscosity

Viscosity of various formulated gels was found in the range of 234-275 centipoise.

\begin{tabular}{|c|c|c|c|c|}
\hline $\begin{array}{c}\text { Formu- } \\
\text { lation }\end{array}$ & pH & $\begin{array}{c}\text { Viscosity } \\
\text { (c.ps) }\end{array}$ & $\begin{array}{c}\text { Extrud- } \\
\text { ability }\end{array}$ & $\begin{array}{c}\text { Spreadabil- } \\
\text { ity } \\
\text { (g.cm/sec) }\end{array}$ \\
\hline \multirow{3}{*}{ IPN6 } & $5.7 \pm 0.10$ & 234 & Good & $0.108 \pm 0.02$ \\
\cline { 2 - 5 } & $6.4 \pm 0.21$ & 254 & Good & $0.345 \pm 0.104$ \\
\cline { 2 - 5 } & $6.6 \pm 0.134$ & 275 & Good & $0.524 \pm 0.219$ \\
\hline
\end{tabular}

Table 10: Evaluation parameters for pronoiosomal gel.

The $\mathrm{pH}$ of the prepared proniosomal gels was found to be 6.6 The viscosity of the gel formulation IPN6 has shown optimum viscosity as it contain vesicles made up of the concentration soyalecithin. The other two formulations showed decreased viscosities due to stabilization of water molecules by high lecithin concentration. The spreadability of the gels was found to be $0.108,0.345$, and 0.524 . The extrudability of the gel was found to be good and satisfactory.

In-vitro drug diffusion studies

\begin{tabular}{|c|c|c|}
\hline S. No. & Time intervals & \% Drug diffusion (n = 3) \\
\hline 1. & 15 & $12.89 \pm 0.153$ \\
\hline 2. & 30 & $15.80 \pm 0.115$ \\
\hline 3. & 45 & $21.18 \pm 0.126$ \\
\hline 4. & 60 & $27.13 \pm 0.231$ \\
\hline 5. & 120 & $35.31 \pm 0.146$ \\
\hline 6. & 180 & $48.54 \pm 0.257$ \\
\hline 7. & 240 & $56.59 \pm 0.262$ \\
\hline 8. & 300 & $64.34 \pm 0.152$ \\
\hline 9. & 360 & $73.65 \pm 0.296$ \\
\hline 10. & 420 & $80.71 \pm 0.118$ \\
\hline 11. & 480 & $89.23 \pm 0.163$ \\
\hline
\end{tabular}

Table 11: In-vitro drug diffusion studies for proniosomal gel.

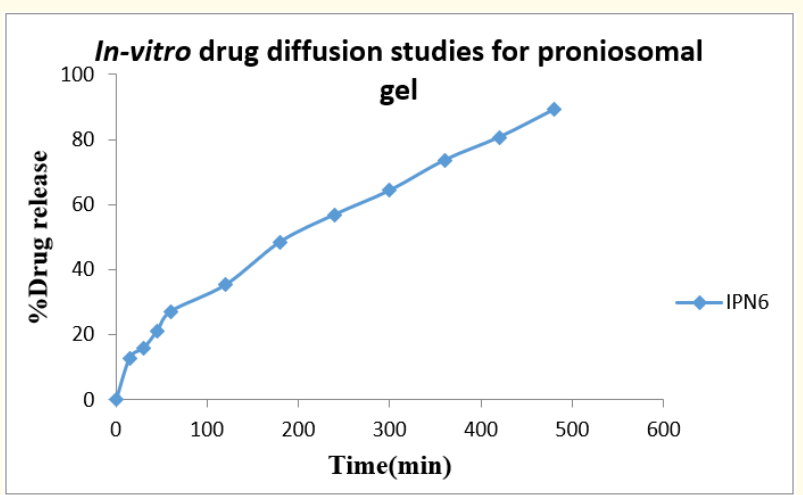

Figure 25: In- vitro drug diffusion studies for proniosomal gel.

The permeation of drug from proniosomal gels containing Span 20 is high compared to that of Tween 20, Propylene glycol Monocaprylate, and Glyceryl monolinoleate. They posses low phase transition temperature and form less permeable rigid bilayers than Span 20. Hence, fast drug release was observed in case of itraconazole proniosomal gels prepared using Span 20. In addition, lecithin acted as penetration enhancer. Sustained drug release pattern was observed with itraconazole proniosomal gel prepared using Span 20. The percent drug release at the end of $8 \mathrm{~h}$ was found to be 89.23\% for IPN6 Formulation.

\section{Summary and Conclusion}

Proniosomes are dry formulation of water soluble carrier particles that are coated with surfactant. They are rehydrated to form niosomal dispersion immediately before use on agitation in hot aqueous media within minutes. Proniosomes are physically stable during storage and transport. Drug encapsulated in vesicular structure of proniosomes prolong the existence of drug in the systematic circulation and enhances the penetration into target tissue and reduce toxicity.

The materials used in the formulation involves Non-ionic surfactants which act as vesicle forming component. Because of its biocompatible nature it was selected for forming of the vesicular carriers. Soyalecithin and cholesterol act as membrane stabilizers. and Ethanol as permeation enhancer. Phospholipid in this formulation maintains structural integrity of the lipid structure and can 
incorporate both hydrophilic and lipophilic drugs. Cholesterol is selected as a stabilizer.

The Itraconazole proniosomes prepared by co-acervation phase separation method. By using soyalecithin, cholesterol. Non-ionic surfactants. The Proniosomal dispersions were stored in well closed container to avoid auto oxidation of the lipid. Formulations were characterized and evaluated by FTIR, microscopic studies, particle size and zeta analysis, entrapment efficiency and in vitro drug release studies.

FTIR studies were performed for physical mixtures in order to determine whether there is any incompatibility between the lipid, drug and excipients used in the formulation. The studies revealed that there was no interaction between the materials used in the formulation and were selected for further studies. Microscopic revealed the presence of proniosomal vesicles in the formulations.

Zeta potential is the measure of the magnitude of the electrostatic or charge repulsion or attraction between particles and is known to effect the stability of formulations. Particle size and zeta potential of the formulation were determined using zeta sizer. The particle size is $0.5 \mathrm{~nm}$ and zeta potential of formulation was found to be $-45 \mathrm{mv}$. respectively. The value of zeta potential indicates the presence of sufficient charge to inhibit aggregation of proniosomes due to electric repulsion. This indicates that the formulation is stable.

The Entrapment efficiency studies were performed for all the formulations and the studied revealed the amount of drug entrapped in the formulations. So, that it can be said that the drug was available in the formulation. The entrapment efficiency of formulations was in the range of $62.05-76.68 \%$.

In vitro drug release studies of formulations were carried out with dissolution apparatus to determine the amount of drug release from the formulation and the availability of drug for absorption. The IPN6 formulation showed maximum drug release and the drug release was in the range of $13.62 \%-90.10 \%$.

The drug content of the proniosomal formulations was performed and the drug content of the gel was in the range of $77.62 \%$ - 99.55\%. These studies revealed the amount of drug present in the formulation.
The formulations showing maximum percentage of entrapment efficiency and drug release from all the four sets were selected for incorporation into carbopol and aloe vera gel base. The Proniosomal gels were prepared with $1 \%$ of carbopol and $1 \%$ of aloe vera gel. The prepared proniosomal gels were evaluated for organoleptic character, $\mathrm{pH}$, viscosity, spreadability, extrudability, drug content and drug diffusion studies.

Among all the four formulations IPN6 gel is homogenous, white with good occlusive and washability properties. The $\mathrm{pH}$ of the formulations was found to be 6.4. The spreadability and extrudability were found to be effective i.e. they showed best results for spreadability and extrudability.

In vitro drug diffusion studies were carried out to reveal the amount of drug perfusing through the membrane and to determine the availability of drug at the site of application. The maximum of drug was diffused from IPN6 formulation when compared with other formulations. The diffusion of drug from the proniosomal gel was in the range of $89.23 \%$.

Anti fungal screening studies were performed for Itraconazole proniosomal gel against Candida albicans. The results of this study revealed that the proniosomal gel is efficient in inhibiting the growth of fungal species. The zone of inhibition was found to be 1.5 $\mathrm{cm}$ after 5 days of incubation.

\section{Bibliography}

1. Anahita Fathi azarbayjani., et al. "Transdermal Delivery of Haloperidol by Proniosomal Formulations with Non-ionic Surfactants". Biological and Pharmaceutical Bulletin 32.8 (2009): 1453-1458.

2. Adnan Azeem., et al. "Feasibility of Proniosomes-Based Transdermal Delivery of Frusemide: Formulation Optimization and PharmacoteXC Xchnical Evaluation". Pharmaceutical Development and Technology 1.3 (2008): 155-163.

3. D Nagasamy Venkatesh., et al. "A Superior Drug Delivery System". International Journal of Pharmaceutical Sciences and Drug Research 6.3 (2014): 178-182.

4. Dr Sanju Nanda., et al. "Formulation, evaluation, and optimization of transdermal gel of ketorolac tromethamine using face centered central composite design". International Journal of Pharmacy and Pharmaceutical Sciences 6.4 (2014): 133-139. 
5. GV Radha., et al. "A review on proniosomal drug delivery system for targeted drug action". Journal of Basic and Clinical Pharmacy 4.2 (2013): 42-48.

6. Gagandeep Benipal. "Design, Development and Evaluation of Proniosomal Gel of an Antifungal Drug-Ketoconazole". International Journal of Pharmaceutical Sciences Review and Research 31.2 (2015): 265-272.

7. HO Ammara., et al. "Proniosomes as a carrier system for transdermal delivery of tenoxicam". International Journal of Pharmaceutics 405 (2011): 142 -152.

8. Ibrahim A Alsarra. "Evaluation of proniosomes as an alternative strategy to optimize piroxicam transdermal delivery". Journal of Microencapsulation 26.3 (2009): 272-278.

9. Itraconazole-Drug bank (2016).

10. Prabhakar Reddy Veerareddy and Sharan Kumar Reddy Bobbala. "Enhanced oral bioavailability of isradipine via proniosomal systems". Drug Development and Industrial Pharmacy (2012): 1-9.

11. Reena Thakur., et al. "Proniosomal transdermal therapeutic system of losartan potassium: development and pharmacokinetic evaluation". Journal of Drug Targeting 17.6 (2009): 442449.

12. Shweta Vashist., et al. "Formulation and evaluation of proniosomal gel of diclofenac sodium by using 32 factorial design". International Journal of Biopharmaceutics 6.1 (2015): 48-54.

13. Sonam Ajay Singh., et al. "Proniosomes: a recent advancement in vesicular drug delivery system". World Journal of Pharmaceutical Research 4.4 (2015): 1671-1689.

14. Srividhya Vardhani $\mathrm{CH}$ and Nirosha M. "Formulation and Evaluation of Topical Proniosomal Gel of an Anti-Fungal DrugItraconazole". International Journal of Current Trends in Pharmaceutical Research 4.6 (2016): 307-313.

15. Thulasi Chowdary G., et al. "In vitro Dynamics of Ibuprofen Incorporated Proniosomal Gel". Indian Journal of Pharmaceutical Education and Research 47.40 (2013): 59-64.

16. Yasam Venkata Ramesh., et al. "Proniosomes: A Novel Nano Vesicular Transdermal Drug Delivery". Journal of Pharmaceutical Sciences and Research 5.8 (2013): 153-158.

\section{Assets from publication with us}

- Prompt Acknowledgement after receiving the article

- Thorough Double blinded peer review

- Rapid Publication

- Issue of Publication Certificate

- High visibility of your Published work

Website: www.actascientific.com/

Submit Article: www.actascientific.com/submission.php

Email us: editor@actascientific.com

Contact us: +919182824667 